\title{
Effects of prepartum dietary cation-anion difference intake on production and health of dairy cows: A meta-analysis
}

\author{
I. J. Lean, ${ }^{1,2 *}$ J. E. P. Santos, ${ }^{3}$ E. Block, ${ }^{4}$ and H. M. Golder ${ }^{1,2}$ \\ ${ }^{1}$ Scibus, Camden, NSW, Australia 2570 \\ ${ }^{2}$ Faculty of Veterinary Science, The University of Sydney, Camden, NSW, Australia 2570 \\ ${ }^{3}$ Department of Animal Sciences, University of Florida, Gainesville 32611 \\ ${ }^{4}$ Arm \& Hammer Animal Nutrition, Princeton, NJ 08543
}

\section{ABSTRACT}

Prepartum diets influence cow performance for weeks to months postpartum. This observation leads to questions about milk yield and physiological and health responses to diets with negative dietary cation-anion difference (DCAD). Further, responses to increased intake of a diet with lower DCAD (Eq/d) have not been explored using meta-analysis. Our objectives were to explore the effects of prepartum DCAD intake on metabolism and production and health as well as the potential for differences in intake of other macrominerals to influence responses to differences in DCAD intake using classical meta-analytical methods. Not all treated groups were fed a diet with negative DCAD, and the effect studied is that of reducing the DCAD. We hypothesized that reducing DCAD intake would improve Ca metabolism and postpartum performance. We used a maximum of 58 comparisons from 31 experiments and a total of 1,571 cows. Intakes of DCAD were $2.28 \mathrm{Eq} / \mathrm{d}$ and $-0.64 \mathrm{Eq} / \mathrm{d}$ for the control, higher DCAD and treated, lower DCAD groups, respectively. Diets with lower DCAD reduced urine $\mathrm{pH}$ [standardized mean difference $(\mathrm{SMD})=1.90$ and weighted mean difference (WMD) $-1.23 \mathrm{pH}$. Intake of lower DCAD decreased prepartum DMI $(\mathrm{SMD}=0.23 ; \mathrm{WMD}=0.29 \mathrm{~kg} / \mathrm{d})$, increased postpartum DMI $(\mathrm{SMD}=0.40 ; \mathrm{WMD}=0.63$ $\mathrm{kg} / \mathrm{d})$, and increased milk yield $(\mathrm{SMD}=0.172)$. However, we found an interaction with parity; diets with lower DCAD increased milk yield in parous cows (SMD $=0.29 ; \mathrm{WMD}=1.1 \mathrm{~kg} / \mathrm{d}$ ) but resulted in numerically lower milk yield in nulliparous cows $(\mathrm{SMD}=-0.20$; $\mathrm{WMD}=1.28 \mathrm{~kg} / \mathrm{d}$ ) compared with controls. The FCM yield increased with treatment $(\mathrm{SMD}=0.12 ; \mathrm{WMD}=$ $0.56 \mathrm{~kg} / \mathrm{d}$ ); however, yield of treated cows tended to be greater in parous cows but smaller for nulliparous cows

Received March 19, 2018.

Accepted October 31, 2018.

*Corresponding author: ianl@scibus.com.au compared with controls. Milk fat percentage, milk fat yield, and milk protein percentages were not affected by treatment, although milk protein yield tended to increase in cows fed the lower DCAD diet (SMD = $0.21 ; \mathrm{WMD}=0.02 \mathrm{~kg} / \mathrm{d}$ ). Treatment increased blood $\mathrm{Ca}(\mathrm{SMD}=0.53 ; \mathrm{WMD}=0.13 \mathrm{mM})$ and $\mathrm{P}(\mathrm{SMD}=$ $0.40 ; \mathrm{WMD}=0.13 \mathrm{mM}$ ) on the day of calving and Ca postpartum $(\mathrm{SMD}=0.36 ; \mathrm{WMD}=0.06 \mathrm{mM})$. Treated cows had smaller concentration of blood BHB before calving than controls $(\mathrm{SMD}=-0.39 ; \mathrm{WMD}=-0.04$ $\mathrm{m} M$ ). Reducing DCAD in cows resulted in decreased risks of clinical hypocalcemia (risk ratio $=0.60$ ) and retained placenta (risk ratio $=0.59$ ), and reduced the odds of metritis (odds ratio $=0.46$ ) and overall disease $(\mathrm{OR}=0.61)$. We observed no effect on risk of abomasal displacement or mastitis and no effect of differences between treated and control cows in Ca intake $(\mathrm{g} / \mathrm{d})$ on the outcomes evaluated. A positive role for increased $\mathrm{Mg}$ intake between groups for increased milk fat yield and in reducing the risk of retained placenta was identified. Diets with lower DCAD improved performance of parous dairy cows, and our findings suggest a need for more studies on the effects of a lower DCAD on nulliparous transition cows.

Key words: dietary cation-anion difference, hypocalcemia, meta-analysis, production

\section{INTRODUCTION}

The potential for diets fed to dairy cows before calving that provide a negative DCAD measured in milliequivalents per kilogram to improve blood Ca concentrations or reduce the risk of clinical hypocalcemia or milk fever has been long recognized (Ender et al., 1971; Dishington, 1975; Block, 1984). These diets, fed for a limited time before calving, have a prolonged positive effect on dairy cow production and health that extends into lactation (Block, 1984; DeGroot et al., 2010). Lean et al. (2014) found that when diets with lower DCAD $(\mathrm{mEq} / \mathrm{kg})$ were fed before calving, milk yield increased in multiparous but not nulliparous cows. Lean et al. 
(2014) suggested that the mechanisms that lead to prolonged milk yield responses and better health following a limited period, typically $25 \mathrm{~d}$, of feeding diets lower in DCAD require further exploration to both understand and possibly enhance these responses.

Meta-analyses have been conducted to determine the dietary factors that reduced the risk of clinical hypocalcemia (Oetzel, 1991; Enevoldsen, 1993; Lean et al., 2006) based on percentage inclusions of minerals and, specifically, the DCAD of diet (Charbonneau et al., 2006). These studies confirmed a positive linear effect of DCAD in increasing the risk of clinical hypocalcemia (Charbonneau et al., 2006; Lean et al., 2006). Lean et al. (2006) also identified a quadratic association of dietary $\mathrm{Ca}$ concentrations on clinical hypocalcemia risk, with the greatest risk occurring at approximately $1.10 \% \mathrm{Ca}$ and the smallest risk with $\mathrm{Ca}$ at approximately less than $0.50 \%$ or more than $1.60 \%$ of the diet. Those authors also found linear associations of $\mathrm{Mg}$ and $\mathrm{P}$ concentrations and length of exposure to the diets on risk of milk fever. Consequently, diets that contained $\mathrm{Mg}$ at concentrations greater than $0.40 \%$, Ca at $0.60 \%$, $\mathrm{P}$ at $<0.40 \%$ with a DCAD less than $-100 \mathrm{mEq} / \mathrm{kg}$ and fed for $21 \mathrm{~d}$ have been recommended as being suitable to prevent clinical hypocalcemia (DeGaris and Lean, 2008). Previous meta-analyses have not examined the effect of reducing DCAD on production and disease when evaluated in treated and control groups. Although it is clear from early experiments (Ender et al., 1971; Dishington, 1975; Block, 1984) and metaanalyses (Oetzel, 1991; Charbonneau et al., 2006; Lean et al., 2006) that diets with negative DCAD reduce the risk of clinical hypocalcemia or hypocalcemia and acidify urine, other effects of DCAD have not been examined in detail or using robust measurement of DMI and minerals. Some papers lack detail of DMI and measured mineral content of diets. Lean et al. (2014) evaluated milk yield responses to DCAD treatments, but the database was derived from a subpopulation of a previous meta-analytical study (Lean et al., 2006); as such, a need exists to evaluate more recent experiments to assess this effect. A need also exists to evaluate the effect of dietary mineral inclusions, expressed as a percentage of dietary DM, on periparturient disorders other than clinical hypocalcemia, milk yield and components, and on mineral and energy metabolism; these are addressed, specifically and as an essential focus of this paper, and also in a companion paper (Santos et al., 2019).

The potential for diet to influence energy metabolism is of particular interest, as a series of murine studies demonstrated the substantial influence of bone and $\mathrm{Ca}$ metabolism on energy metabolism (Lee et al., 2007). The findings in mice are supported by observations in cows (Lean et al., 2014; Martinez et al., 2014; Rodney et al., 2018a,b) and may represent an important part of the adaptation to the challenges of late gestation and early lactation (Lean et al., 2014). Adaptive failures to lactation are reflected in hypocalcemia and milk fever, but also in increased risk of other metabolic diseases (Curtis et al., 1983; Martinez et al., 2012) and reduced pregnancy to AI and increased interval from calving to pregnancy associated with clinical hypocalcemia and hypocalcemia (Borsberry and Dobson, 1989; Martinez et al., 2012).

We hypothesized that reducing the DCAD of the diet, measured in intake of equivalents per day and reflected in differences between treated and control cows, would reduce the risk of clinical hypocalcemia and hypocalcemia and increase milk yield. Further, we examined the effects of differences in DCAD intake between treated and control cows on composition and yield of milk components. Moreover, the outcomes of differences in DCAD fed prepartum between treated and control cows on periparturient disorders, including retained placenta, metritis, mastitis, and displaced abomasum, were evaluated, as well as the effects of DCAD on indicators of energy metabolism including concentrations of fatty acids, BHB, and glucose in blood. The objectives of our study were to explore the effects of prepartum diets differing in DCAD intake on concentrations of minerals and metabolites in blood, and implications to postpartum performance and health and the potential for differences of intake in other dietary macrominerals to influence responses to differences in DCAD intake.

\section{MATERIALS AND METHODS}

\section{Search of the Published Literature}

A comprehensive search of the literature published in English from 1973 to 2017 was conducted to identify experiments with transition dairy cows that were fed prepartum diets in which the mineral composition was manipulated to alter the DCAD or were fed acidogenic diets in which the concentration of $\mathrm{Ca}, \mathrm{P}$, or $\mathrm{Mg}$ was manipulated prepartum. Responses of interest included prepartum DMI, postpartum productive performance, concentrations of minerals and blood metabolites associated with energy metabolism during the peripartum period, and incidence of health problems. Details of the literature search can be found elsewhere in the companion manuscript (Santos et al., 2019).

\section{Inclusion and Exclusion Criteria}

The criteria for inclusion of experiments was that treatment interventions manipulated the DCAD of 
prepartum diets or that prepartum cows had been fed diets supplemented with acidogenic products and that the concentrations of $\mathrm{Ca}, \mathrm{P}$, or $\mathrm{Mg}$ were manipulated. Only randomized design experiments with individual feeding of prepartum dietary treatments to cows were included. Dietary interventions had to be described relative to DCAD and concentrations of $\mathrm{Ca}, \mathrm{P}$, and $\mathrm{Mg}$. The DCAD was calculated as milliequivalents of $\mathrm{K}$ and $\mathrm{Na}$ minus milliequivalents of $\mathrm{Cl}$ and $\mathrm{S}$ per kilogram of diet DM. Experiments where cows were force-fed by oral dosing or through ruminal cannula were excluded. Cows had to be fed for ad libitum intake. For our study, only experiments containing a comparison that had DCAD manipulated before calving and a control group were used. Details of the search literature can be found in the companion manuscript (Santos et al., 2019).

\section{Experiments Included}

Figure 1 depicts a PRISMA diagram (Moher et al., 2009) of the flow of data collection for the metaanalysis. After the initial search and screening, 70 full articles (experiments) were assessed for eligibility and 28 of them were excluded because of the following reasons: abstract in English but full article in Chinese (2 experiments); oral or ruminal dosing of acidogenic products (4 experiments); changeover design (1 experiment); group feeding prepartum (7 experiments); crossover design(1 experiment); dry nonpregnant cow (2 experiments); lack of details of prepartum diets (4 experiments); intake of prepartum diets not reported (2 experiments); only urine $\mathrm{pH}$ reported (2 experiments); pasture feeding (1 experiment); data not reported for individual comparisons (1 experiment); treatments applied postpartum (1 experiment); and experiments that did not manipulate DCAD (11 experiments). A total of 31 experiments with 58 treatment comparisons were included in the meta-analysis. Of these experiments, only 5 included nulliparous cows only. Outcomes were not available for all responses evaluated in all 31 experiments, and details of the number of outcomes included in each analysis is provided in the manuscript. A list of the experiments included in the meta-analysis is depicted in Table 1.

\section{Data Extraction}

For responses with continuous data, the experiments had to report individual comparison least squares means and standard error of the mean or means and standard deviation. Frequency data were collected for treatments with the number of affected and nonaffected individuals for the responses evaluated. Methods for data extraction are reported elsewhere (Santos et al., 2019).

Data collected for each comparison within experiment included number of cows, parity group prepartum as nulliparous (lactation 0 prepartum, lactation 1 postpartum) or parous cows (lactation $>0$ prepartum, multiparous postpartum), breed of cow (Holstein or other), treatment days prepartum, type of acidogenic product fed (none, acidogenic salts, or commercial acidogenic products), milking frequency, and the macromineral concentration of the prepartum diet $(\mathrm{Ca}, \mathrm{P}, \mathrm{Mg}, \mathrm{K}$, $\mathrm{Na}, \mathrm{Cl}$, and S). Four experiments (Bluel, 2006; Rezac et al., 2014; Wu et al., 2014, 2015) did not separate the results for nulliparous from parous cows. Because of the predominance of cows that had completed at least 1 lactation, they were considered parous cows for data analyses.

Responses collected included prepartum $\mathrm{BW}$ and urine $\mathrm{pH}$; postpartum DMI, yields of milk and FCM, concentrations and yields of fat and protein in milk, and $\mathrm{BW}$; incidence of clinical hypocalcemia, retained placenta, metritis, mastitis, and displaced abomasum; concentrations of $\mathrm{Ca}, \mathrm{Mg}$, and $\mathrm{P}$ in blood of cows before calving, on the day of calving, and postpartum; and concentrations of glucose, fatty acids, and BHB in blood of cows before and after calving. Responses from different publications were standardized to the same unit using the metric system, percent, and, for concentrations of analytes in blood, as millimolar. The term clinical hypocalcemia was defined using the definitions from the experiments contributing to this experiment and varies within those experiments from clinical signs of milk fever without supporting blood measures to the use of $\mathrm{Ca}$ concentrations in blood taken at or close to calving and independent of clinical signs. The variability in these definitions is inevitable without access to the original data used in the experiments to define milk fever.

\section{Statistical Analysis}

Data were structured to allow a classical metaanalytical evaluation of differences in responses of the experimental groups to be assessed. For each experiment, the treatment with the largest DCAD was considered the control, whereas treatments with a lower DCAD were considered the treated group. Therefore, we assessed the effect of reducing the DCAD on the responses of interest. A Student's t-test was used to evaluate differences in intake of concentrations and amounts of minerals between treated and control groups (Table 2). We noticed a hierarchical structure in these data, as many experiments used multiple treat- 
ment comparisons. Consequently, dependence within experiment existed, and the effects of experiment and comparison need to be evaluated by meta-regression using multilevel models (St-Pierre, 2001; Hedges et al., 2010; Van den Noortgate et al., 2013).

Variables examined by meta-regression included parity of treatment comparisons, differences between treated and controls in intake $(\mathrm{g} / \mathrm{d}$ or $\mathrm{Eq} / \mathrm{d})$ of $\mathrm{Ca}, \mathrm{P}$, $\mathrm{Mg}$, and DCAD, and quadratic effects of DCAD. We found only 9 comparisons from 5 experiments reporting data for nulliparous cows. Some experiments reported data for nulliparous and parous cows together, and we considered those to be parous cows. Notwithstanding the limited power to evaluate the effects of parity, this effect was tested; however, observations on differences of treatment responses between parity might have a low statistical power.

Model Development. Initial data exploration included production of basic statistics using Stata (Version 15, StataCorp LP, College Station, TX) to examine the data for errors and to estimate the means and measures of dispersion. Normality of the data was examined for continuous variables by visual and statistical appraisal.

Further exploration of the factors that influenced outcomes was conducted using variables that had a $P<0.20$ on univariable correlation analysis with the outcome variables. This method was used to reduce the

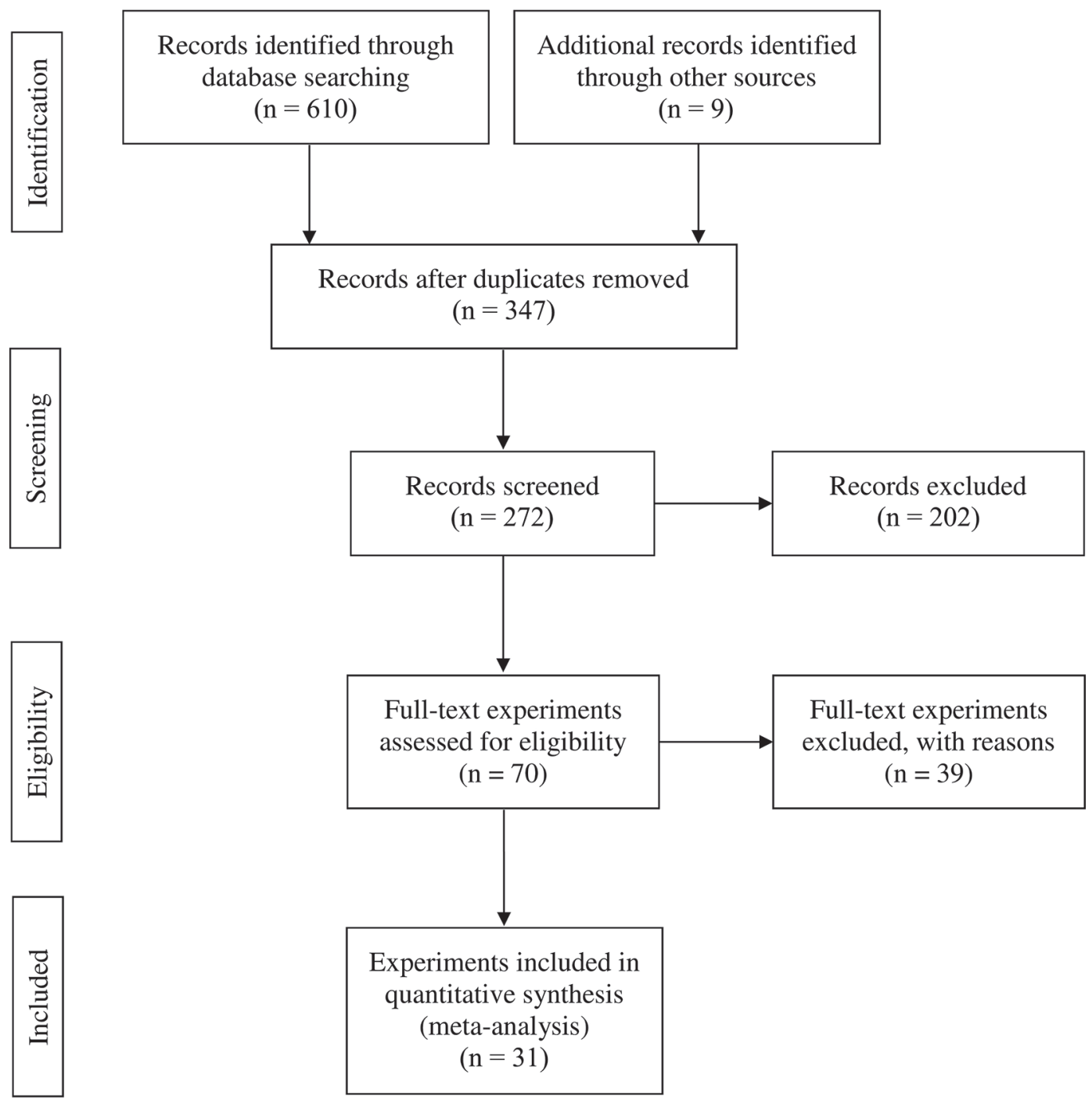

Figure 1. The PRISMA flow (Moher et al., 2009) diagram of the systematic review from initial search and screening to final selection of publications to be included in the meta-analysis. 
Table 1. Summary of experiment comparisons used in the meta-analysis, including reference, parity of cows, number of cows, breed of cows, and difference in DCAD (treated - control) intake

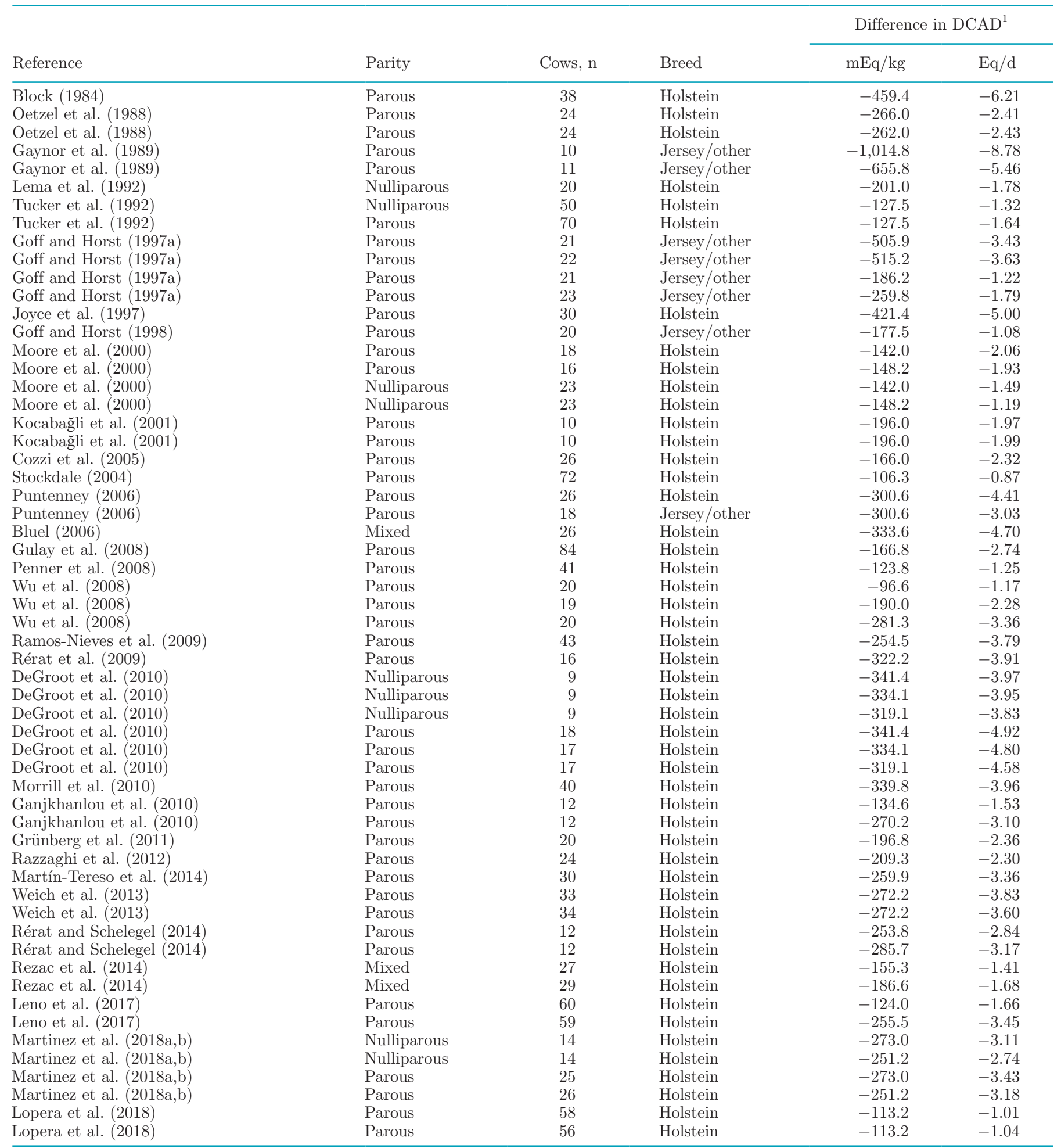

${ }^{1}$ Within each experiment, the diet with largest DCAD value was considered the control and those with lower DCAD were considered the treated $\operatorname{group}(\mathrm{s})$. 
Table 2. Descriptive statistics of mineral composition of diets offered to prepartum cows and intake of minerals according to treatment group ${ }^{1}$

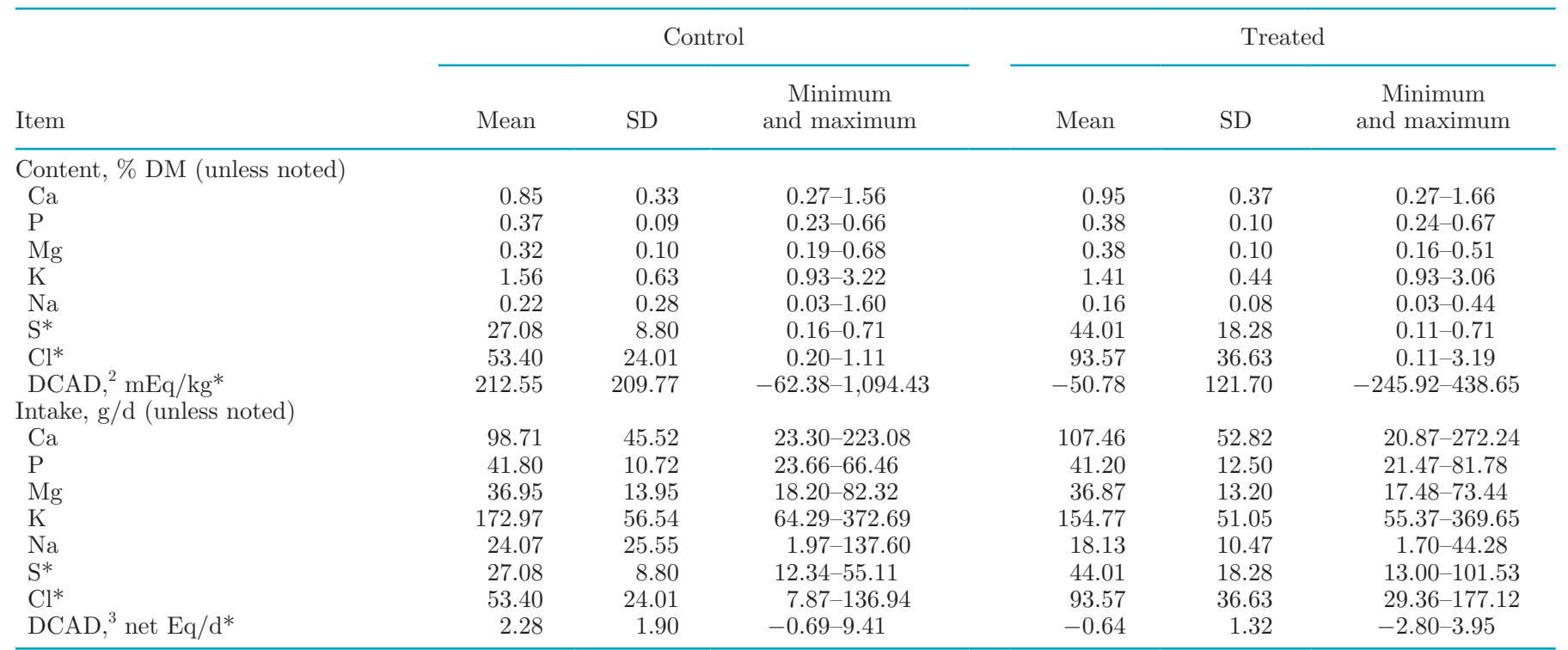

${ }^{1}$ Within each experiment, the diet with the largest DCAD value was considered the control and those with lower DCAD were considered the treated $\operatorname{group}(\mathrm{s})$.

${ }^{2}$ Dietary cation-anion difference calculated as DCAD $=[(\mathrm{mEq}$ of $\mathrm{Na}+\mathrm{mEq}$ of $\mathrm{K})-(\mathrm{mEq}$ of $\mathrm{S}+\mathrm{mEq}$ of $\mathrm{Cl})]$.

${ }^{3}$ Intake of net equivalents (Eq) considered the DCAD of the diet offered and the DMI prepartum; for example, cows fed a diet with $-50 \mathrm{mEq} /$ $\mathrm{kg}$ and DMI of $11 \mathrm{~kg} / \mathrm{d}$ would result in a net Eq intake of $-0.55 \mathrm{Eq} / \mathrm{d}$.

*Differed between control and treatment $(P<0.0001)$.

potential for over-fitting models to the data (Dohoo et al., 2009). The effect of treatment comparison within experiment was examined as a random effect using GLAMM (Stata 14.2) to partition the variance components of the nested model (Rabe-Hesketh and Skrondal, 2005) for milk yield. Treatment comparison within experiment explained $14.9 \%$ of variation in responses, above that explained by experiment alone. Variance attributable to the effect of experiment also explained $14.9 \%$ of the variation in responses.

Stata also was used to analyze differences in responses by standardized mean difference (SMD) analysis, which is also called effect size (ES) analysis; the terms SMD and ES are used interchangeably. These methods have been published in detail in Lean et al. (2009) and Golder and Lean (2016). The difference between treated and control groups means, which is termed comparison in the following description, was standardized using the standard deviation of reference and treatment groups. The SMD estimates were pooled using the DerSimonian and Laird (1986) random effects models. Only random effects models were used, as previous work concluded that when there was uncertainty in the evaluative units caused by clustering of observations, the random effects model was appropriate (White and Thomas, 2005).

A random-effects weighted mean difference (WMD) between treated and control is provided for the con- tinuous variables studied, with the weighting reflecting the inverse of the variance of the treatments included according to the nostandard method in the mean model of Stata to allow an interpretation of treatment effects in familiar units rather than ES.

Assessment of Heterogeneity. Variations among the comparison-level SMD were assessed using a chisquared $\left(\chi^{2}\right)$ test of heterogeneity. Heterogeneity in comparisons reflects underlying differences in clinical diversity of the herds and interventions, differences in experimental design and analytical methods, and statistical variation around responses. The diversity of the herd includes all the nonstudy design aspects of variation, such as facility design, environment, and animal management, that may be measured and controlled for in meta-analysis but are often not reported or measured. Identifying the presence and sources of the heterogeneity improves understanding of the responses to the interventions used. Heterogeneity of results among the comparisons was quantified using the $I^{2}$ statistic (Higgins and Thompson, 2002), which was developed to measure the effect of heterogeneity on a meta-analysis from mathematical criteria that are independent of the number of treatment comparisons and the treatment effect measure. The measure $I^{2}$ is a transformation of the square root of the $\chi^{2}$ heterogeneity statistic divided by its degrees of freedom and describes the proportion 
of total variation in comparison estimates that is due to heterogeneity. Further, $I^{2}$ provides an estimate of the proportion of the true variance of effects of the comparison tau squared $\left(\tau^{2}\right)$ divided by the total variance observed in the comparison (Borenstein et al., 2017) that reflect measurement error. Negative values of $I^{2}$ are assigned a value of 0 ; consequently, the value $I^{2}$ lies between 0 and 100\%. An $I^{2}$ value between 0 and $40 \%$ might not be important, 30 to $60 \%$ may represent moderate heterogeneity, 50 to $90 \%$ might represent substantial heterogeneity, and 75 to $100 \%$ might represent considerable heterogeneity (Higgins and Green, 2011). These broad ranges reflect confidence intervals around $I^{2}$. The robust regression models were the preferred final models and $\tau^{2}$ were $<0.01$ for all final models. Therefore, the only measures of $I^{2}$ retained are those in Figures 1, 2, 3, 4, 5, 6, 7, and 8. When responses to treatments differed between parity group or were of notable similarity, such as DMI postpartum, forest plots were presented showing parous and nulliparous responses.

Meta-Regression. A key focus of meta-analysis is to identify and understand the sources of heterogeneity or variation of response among comparisons; for example, the linear and quadratic effect of DCAD or other mineral intakes on effect size responses. Metaregression analyses were used to explore the source of heterogeneity of response using the individual SMD for each comparison as the outcome and the associated standard error as the measure of variance. Metaregression is also a technique that can formally test whether evidence exists of different effects in different subgroups of treatments (Knapp and Hartung, 2003). We have previously published the equations used in meta-regression (Rabiee et al., 2012) and refer readers to these for a description of meta-regression using the methods of Thompson and Sharp (1999) and Knapp and Hartung (2003).

The hierarchical structure of the effects of comparisons within experiment (Hedges et al., 2010) was evaluated and programmed as "Robumeta" (Stata) and applied by Tanner-Smith and Tipton (2014). Hedges et al. (2010) developed the robust regression models to account for the 2-stage cluster sampling inherent when the ES estimates are derived from a total of $\mathrm{n}=k 1$ $+k 2+\ldots+k m$ estimates from comparisons that were collected by sampling $m$ clusters of experiments; that is, several comparison estimates are derived from the same experiment. Hence, sampling $k j \geq 1$ estimates within the $j$ th cluster for $j=1, \ldots, m$. Briefly, in this test, the mean ES from a series of experiments is described as follows, where, in this case, the regression model has only an intercept $b 1$ and the weighted mean has the form

$$
b 1=\frac{\sum_{j=1}^{m} \sum_{j=1}^{k 1} w i j \mathbf{T} i j}{\sum_{j=1}^{m} \sum_{j=1}^{k 1} w i j},
$$

where $m$ is the total number of studies, $k$ is the total number of comparisons, wij is the weighting for comparisons within experiments, and $\mathbf{T} i j$ is the vector of the ES estimates of comparisons within experiments. If all the estimates in the same experiment are given identical weights, the robust variance estimate $\left(v^{\mathrm{R}}\right)$ reduces to

$$
v^{\mathrm{R}}=\frac{\sum_{j=1}^{m} w_{j}^{2}(\breve{\mathrm{T}} j-b 1)^{2}}{\left(\sum_{j=1}^{m} w j\right)^{2}}
$$

where $\breve{\mathrm{T}} j$ is the unweighted mean of the estimates in the $j$ th cluster, $b 1$ is the estimate of the weighted mean, and $w_{j}$ is the total weight given to estimates in the $j$ th cluster. This is a kind of weighted variance that reduces to $(m-1) / m^{2}$ times the variance when the weights within experiment are identical, and (as $\mathrm{r}=1$ in this case) the robust regression standard error equals $1 / m$ times the variance of $\breve{\mathrm{T}} j$ estimated when the weights are equal. Hedges et al. (2010) highlight several important aspects of the robust model and the underlying assumptions: that the correlation structure of the $\breve{\mathrm{T}} j$ does not need be known to compute the pooled ES or $v^{\mathrm{R}}$, only that the vectors of estimates from different experiments are independent and that regularity conditions are satisfied; the experiment- or comparison-level regressors do not need to be fixed; the theorem is asymptotic based on the number of experiments, rather than the number of comparisons; and the theorem is relatively robust to regularity assumptions. The centered mean effects of covariates within experiment and comparison were evaluated for their effect on the ES for each variable using meta-regression according to the methods outlined by TannerSmith and Tipton (2014) to account for the effect of experiment and comparison and used to predict ES responses to treatment. Univariable and multivariable models were developed to test these effects on ES. The collinearity of these variables was tested using the Collin function of Stata and then a backward stepping regression was used to eliminate variables based on 
retaining only variables with a $P \leq 0.05$. As we found relatively few predictive variables, all were retained in the initial models that included effects centered on experiment and comparison of parity and differences (treated - control) in macromineral intake grams per day, DCAD equivalents per day, and quadratic effects of DCAD.

Publication Bias. Presence of publication bias was investigated using funnel plots, which are a simple scatter plot of the treatment effect estimates from individual

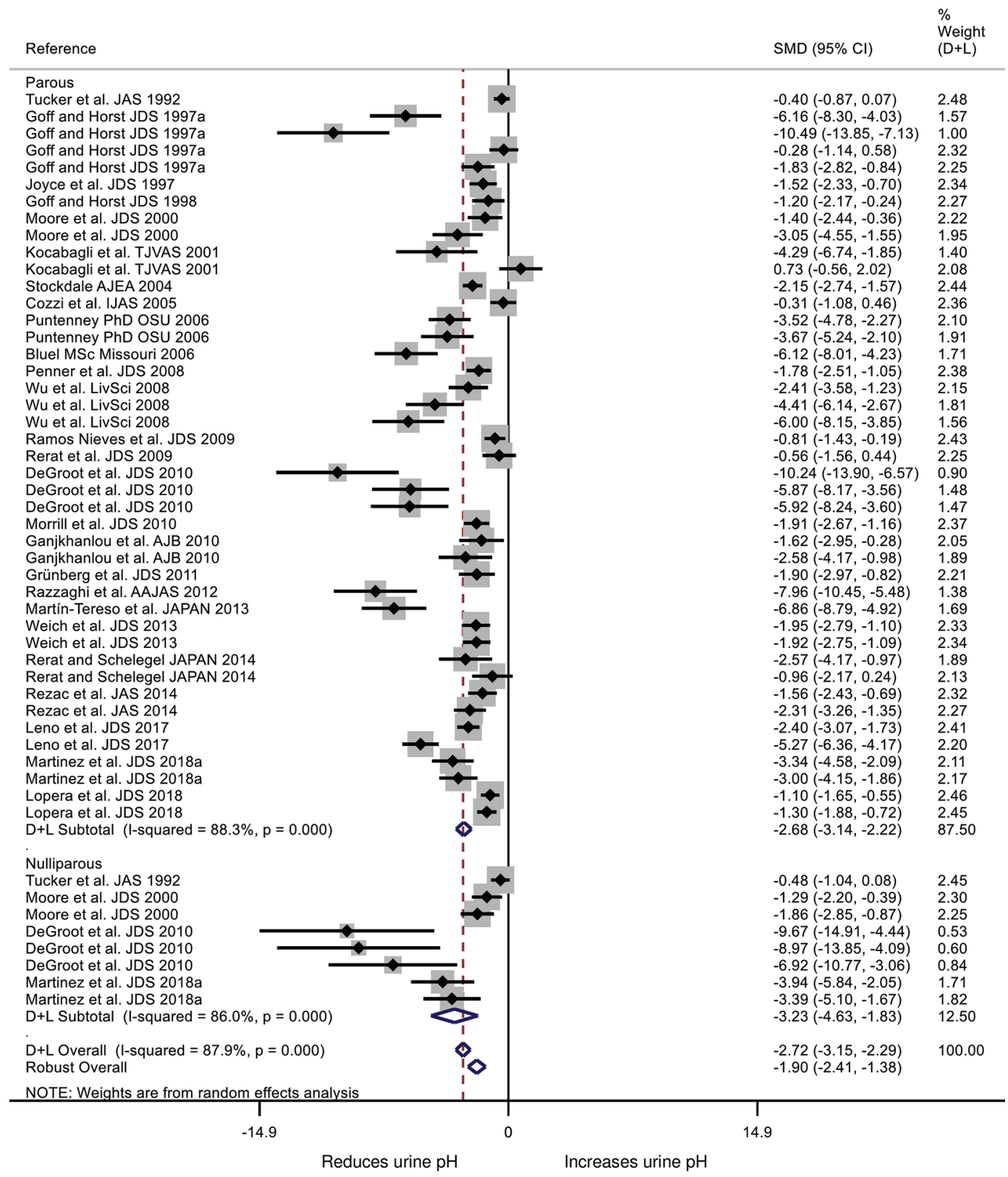

Figure 2. Forest plot of the effect size or standardized mean difference (SMD; standardized using the z-statistic) and $95 \%$ CI of the effect of a lowered DCAD intake $(\mathrm{Eq} / \mathrm{d})$ on urinary $\mathrm{pH}$ in parous and nulliparous dairy cows. The solid vertical line represents a mean difference of zero or no effect. Points to the left of the line represent a reduction in urinary $\mathrm{pH}$, whereas points to the right of the line indicate an increase. Each box around the point effect represents the mean effect size for that comparison and reflects the relative weighting of the comparison to the overall effect size estimate. The larger the box, the greater the comparison contribution to the overall estimate. The weight that each comparison contributed is in the right-hand column. The upper and lower limit of the line connected to the square represents the upper and lower 95\% CI for the effect size. The overall pooled effects size or SMD and 95\% CI pooled using the DerSimonian and Laird (D+L; DerSimonian and Laird, 1986) and robust meta-analytical models (Hedges et al., 2010) methods for random effects models are indicated by the respective diamonds at the bottom. The heterogeneity measure, $I^{2}$, is a measure of variation beyond chance among treatments included in the meta-analysis. The effect of a lower DCAD intake on urine $\mathrm{pH}$ was considerably heterogeneous, as indicated by the $I^{2}$ of $87.9 \%$. 


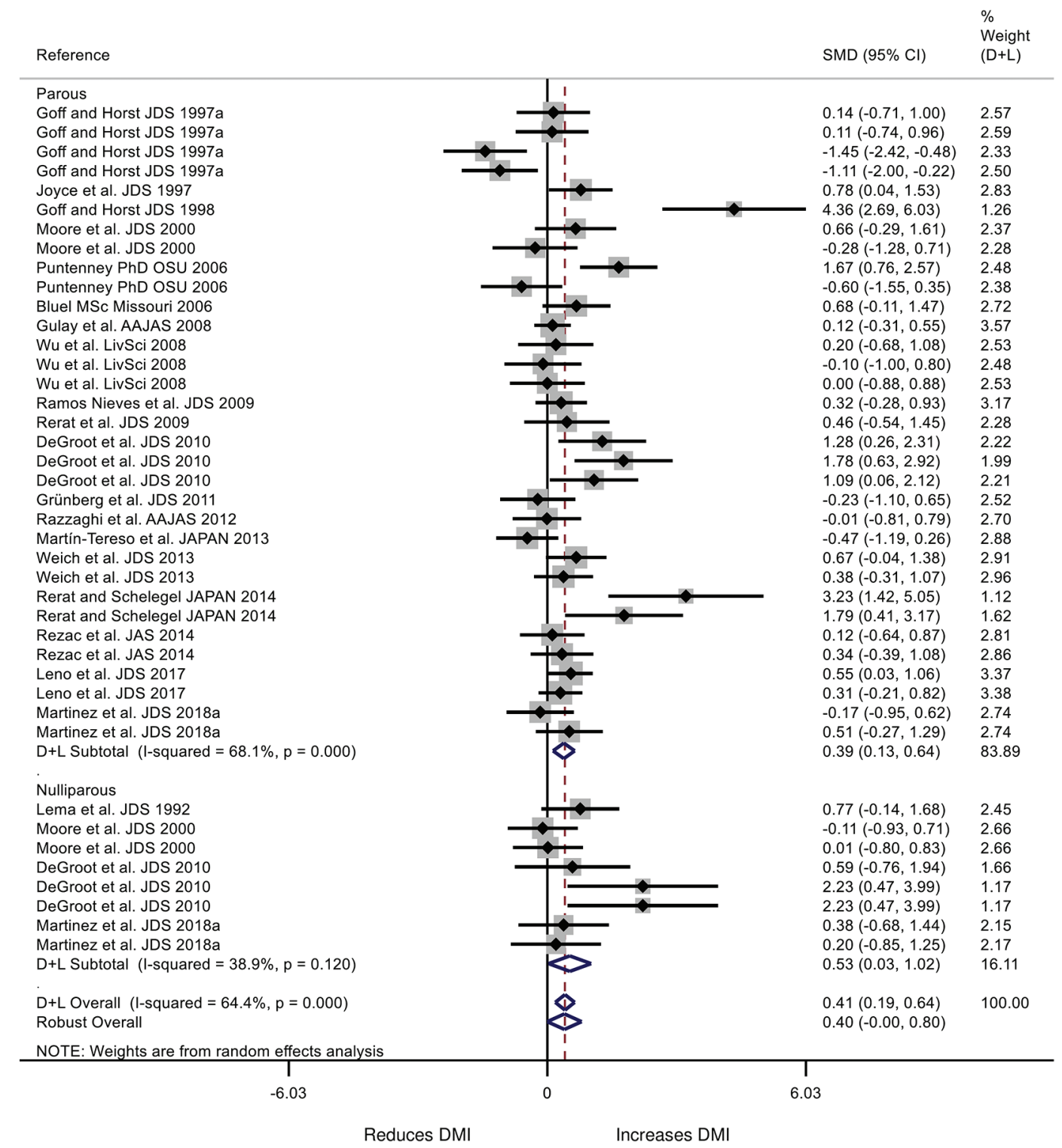

Figure 3. Forest plot of the effect size or standardized mean difference (SMD; standardized using the z-statistic) and $95 \%$ CI of the effect of a lowered DCAD intake (Eq/d) on postpartum DMI in parous and nulliparous dairy cows. The solid vertical line represents a mean difference of zero or no effect. Points to the left of the line represent a reduction in DMI, whereas points to the right of the line indicate an increase. Each box around the point effect represents the mean effect size for that comparison and reflects the relative weighting of the comparison to the overall effect size estimate. The larger the box, the greater the comparison contribution to the overall estimate. The weight that each comparison contributed is in the right-hand column. The upper and lower limit of the line connected to the square represents the upper and lower $95 \%$ CI for the effect size. The overall pooled effects size or SMD and 95\% CI pooled using and robust meta-analytical models (Hedges et al., 2010) methods for random effects models are indicated by the respective diamonds at the bottom. The heterogeneity measure, $\dot{I}^{2}$, is a measure of variation beyond chance among treatments included in the meta-analysis. The effect of a lower DCAD intake on DMI after calving was substantially heterogeneous, as indicated by the $I^{2}$ of $64.4 \%$.

comparisons plotted against comparison precision. The name funnel plot comes from precision of the treatment effect increasing as the size and precision of a study increases. Effect estimates from comparisons with a small number of animal units will scatter more widely at the bottom of the graph and the spread narrows for those with higher numbers of units. In the absence of bias, the plot should approximately resemble a symmetrical (inverted) funnel. If bias exists, for example because smaller comparisons without statistically significant effects remain unpublished, this will lead to an asymmetrical appearance of the funnel plot and a gap will 


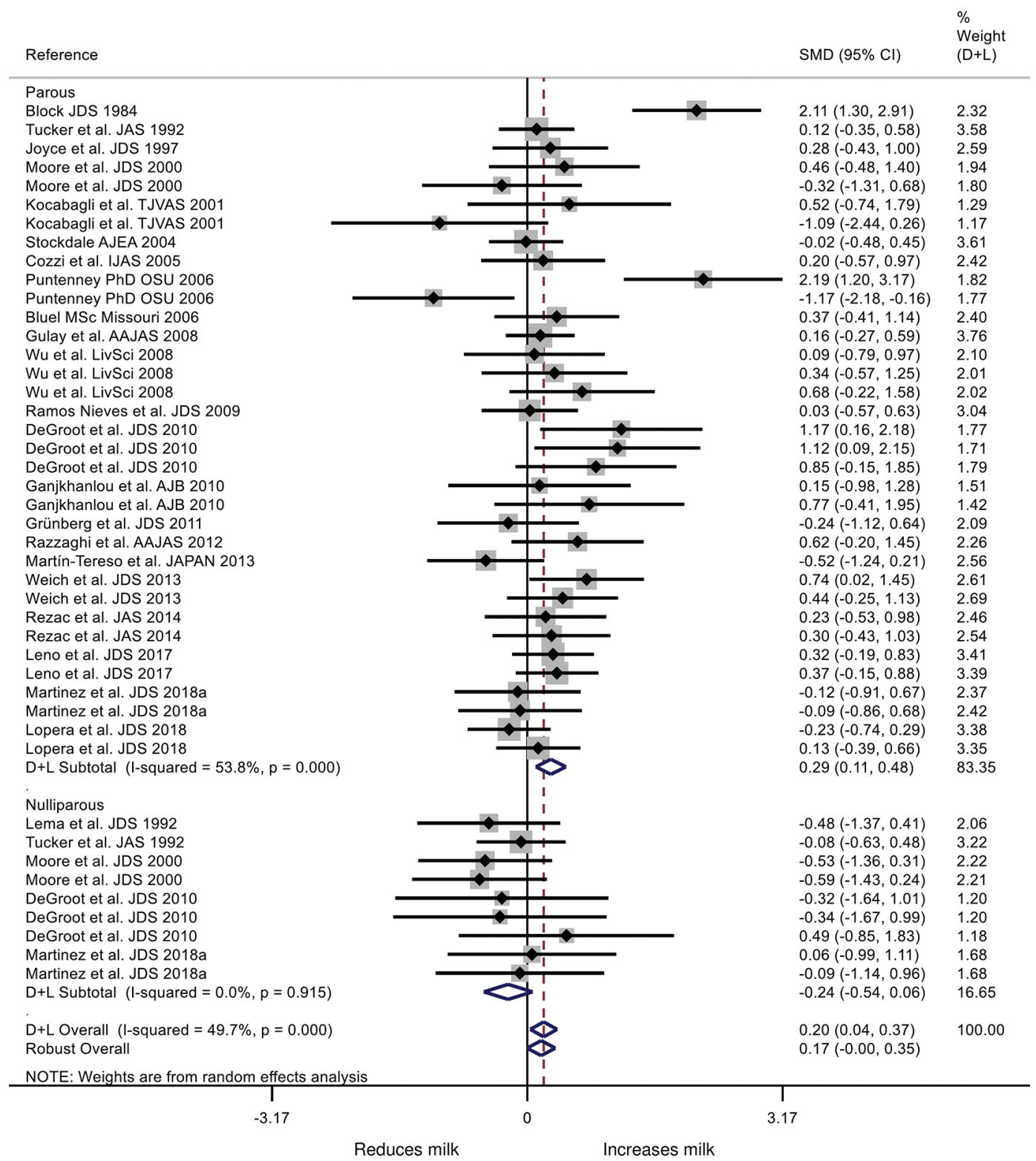

Figure 4. Forest plot of the effect size or standardized mean difference (SMD; standardized using the z-statistic) and 95\% CI of the effect of a lowered DCAD intake $(\mathrm{Eq} / \mathrm{d})$ on milk yield in parous and nulliparous dairy cows. The solid vertical line represents a mean difference of zero or no effect. Points to the left of the line represent a reduction in milk yield, whereas points to the right of the line indicate an increase. Each box around the point effect represents the mean effect size for that comparison and reflects the relative weighting of the comparison to the overall effect size estimate. The larger the box, the greater the comparison contribution to the overall estimate. The weight that each comparison contributed is in the right-hand column. The upper and lower limit of the line connected to the square represents the upper and lower 95\% CI for the effect size. The overall pooled effects size or SMD and 95\% CI pooled using the DerSimonian and Laird (D+L; DerSimonian and Laird, 1986) and robust meta-analytical models (Hedges et al., 2010) methods for random effects models are indicated by the respective diamonds at the bottom. The heterogeneity measure, $I^{2}$, is a measure of variation beyond chance among treatments included in the meta-analysis. The effect of a lower DCAD intake on milk yield was moderately heterogeneous, as indicated by the $I^{2}$ of $49.7 \%$.

be evident in a bottom corner of the graph. In this situation, the effect calculated in a meta-analysis will tend to overestimate the intervention effect. The more pronounced the asymmetry, the more likely it is that the bias will be substantial.

\section{RESULTS}

A maximum of 31 experiments with 58 DCAD treatment comparisons were available after exclusions (Figure 1), representing 1,571 cows, of which 151 were 
nulliparous and the remainder were parous cows. The key criteria for inclusion of experiments were use of a control and treated group in which the DCAD was manipulated in the diet prepartum to result in differ- ences in intake of DCAD (Eq/d) based on measured DMI prepartum. Numbers of experiments and comparisons varied for the different outcomes evaluated and reflected the variation in reported data in the manu-

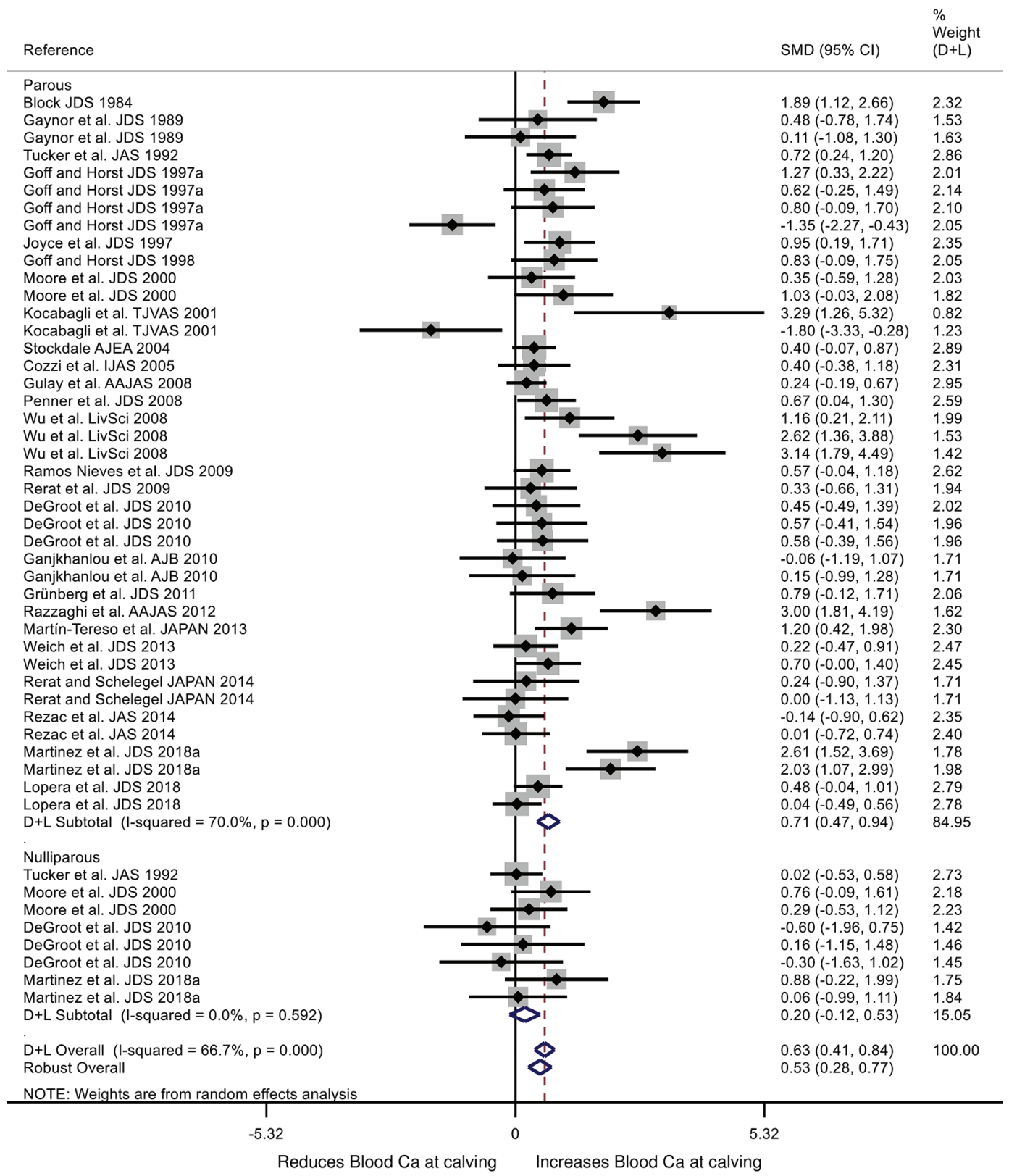

Figure 5. Forest plot of the effect size or standardized mean difference (SMD; standardized using the z-statistic) and 95\% CI of the effect of a lowered DCAD intake $(\mathrm{Eq} / \mathrm{d})$ on blood Ca concentration on the day of calving in parous and nulliparous dairy cows. The solid vertical line represents a mean difference of zero or no effect. Points to the left of the line represent a reduction in Ca in blood at calving, whereas points to the right of the line indicate an increase. Each box around the point effect represents the mean effect size for that comparison and reflects the relative weighting of the comparison to the overall effect size estimate. The larger the box, the greater the comparison contribution to the overall estimate. The weight that each comparison contributed is in the right-hand column. The overall pooled effects size or SMD and 95\% CI pooled using the DerSimonian and Laird (D+L; DerSimonian and Laird, 1986) and robust meta-analytical models (Hedges et al., 2010) methods for random effects models are indicated by the respective diamonds at the bottom. The heterogeneity measure, $I^{2}$, is a measure of variation beyond chance among treatments included in the meta-analysis. The effect of a lower DCAD intake on concentration of Ca in blood at calving was substantially heterogeneous, as indicated by the $I^{2}$ of $66.7 \%$. 
scripts. Table 1 outlines the different experiments used in the meta-analysis. We found no evidence from funnel plot evaluations of any publication bias for any of the outcomes studied.

\section{Dietary Information}

Table 2 provides the means for each of the explanatory and outcome variables for the treated and control groups. We noted little difference in mean concentrations of minerals in the diet with the exception of $\mathrm{Cl}$, $\mathrm{S}$, and DCAD (Table 2), a finding consistent with the planned interventions of the experiments. Similarly, only the daily mean intakes of $\mathrm{Cl}(\mathrm{g} / \mathrm{d}), \mathrm{S}(\mathrm{g} / \mathrm{d})$, and
DCAD $(\mathrm{Eq} / \mathrm{d})$ differed $(P<0.0001)$ between the control and treated groups. Intakes of DCAD were 2.28 and $-0.64 \mathrm{Eq} / \mathrm{d}$ for the control and treated groups, respectively (Table 2). It is important to mention that not all treated groups were fed a diet with negative DCAD, and the effect studied is that of reducing the DCAD, not that of feeding a diet with negative DCAD.

\section{Prepartum DMI, BW, and BCS}

Table 3 provides details of the mean, standard deviation, minimum and maximum DMI, BW, and BCS by treatment group pre- and postpartum. Table 4 provides

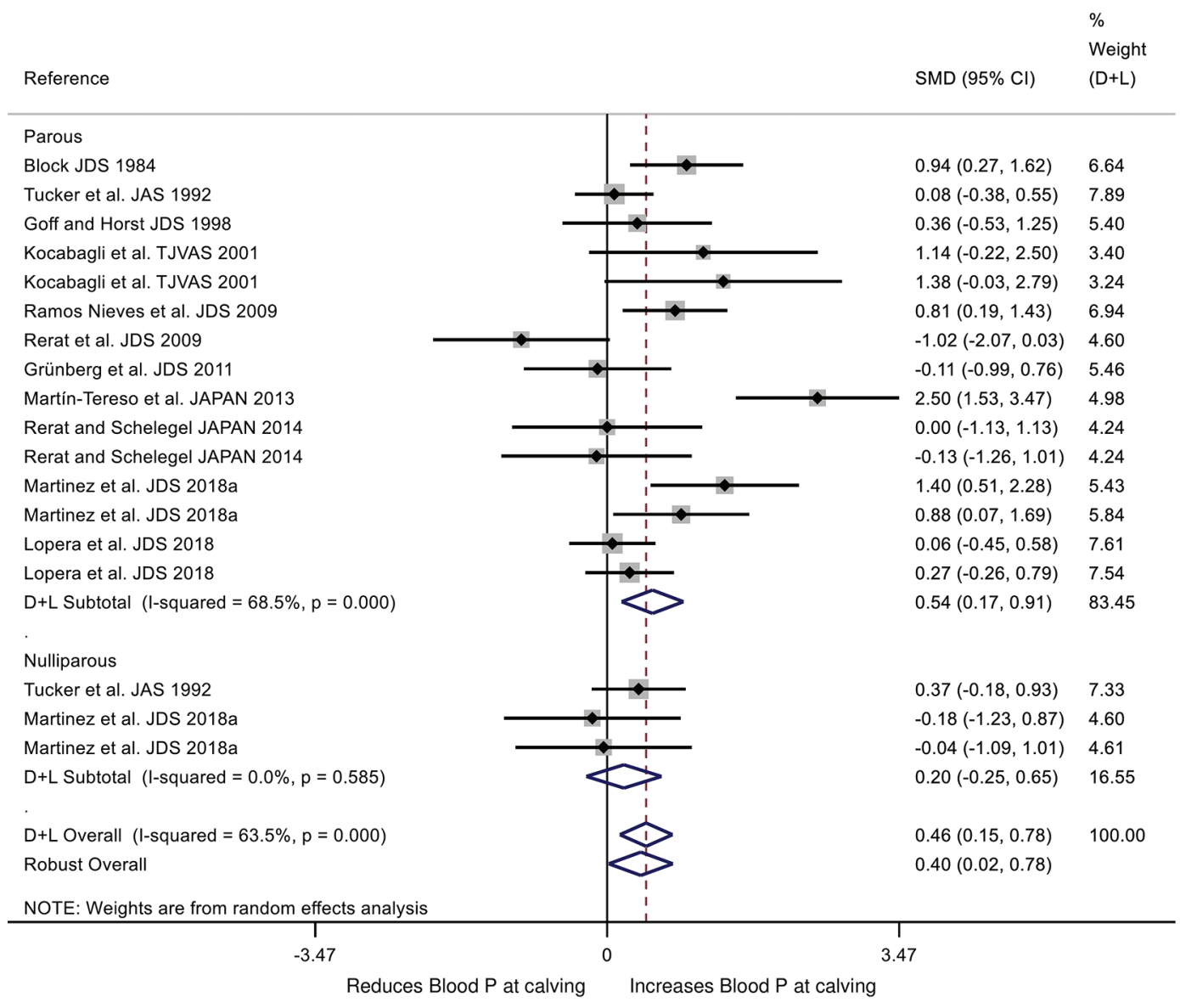

Figure 6. Forest plot of the effect size or standardized mean difference (SMD; standardized using the z-statistic) and $95 \%$ CI of the effect of a lowered DCAD intake (Eq/d) on blood $\mathrm{P}$ concentration on the $\mathrm{d}$ of calving in parous and nulliparous dairy cows. The solid vertical line represents a mean difference of zero or no effect. Points to the left of the line represent a reduction in the difference in $\mathrm{P}$ in blood at calving, whereas points to the right of the line indicate an increase. Each box around the point effect represents the mean effect size for that comparison and reflects the relative weighting of the comparison to the overall effect size estimate. The larger the box, the greater the comparison contribution to the overall estimate. The weight that each comparison contributed is in the right-hand column. The upper and lower limit of the line connected to the square represents the upper and lower 95\% CI for the effect size. The overall pooled effects size or SMD and 95\% CI pooled using the DerSimonian and Laird (D+L; DerSimonian and Laird, 1986) and robust meta-analytical models (Hedges et al., 2010) methods for random effects models are indicated by the respective diamonds at the bottom. The heterogeneity measure, $I^{2}$, is a measure of variation beyond chance among treatments included in the meta-analysis. The effect of a lower DCAD intake on concentration of P in blood at calving was substantially heterogeneous, as indicated by the $I^{2}$ of $63.5 \%$. 


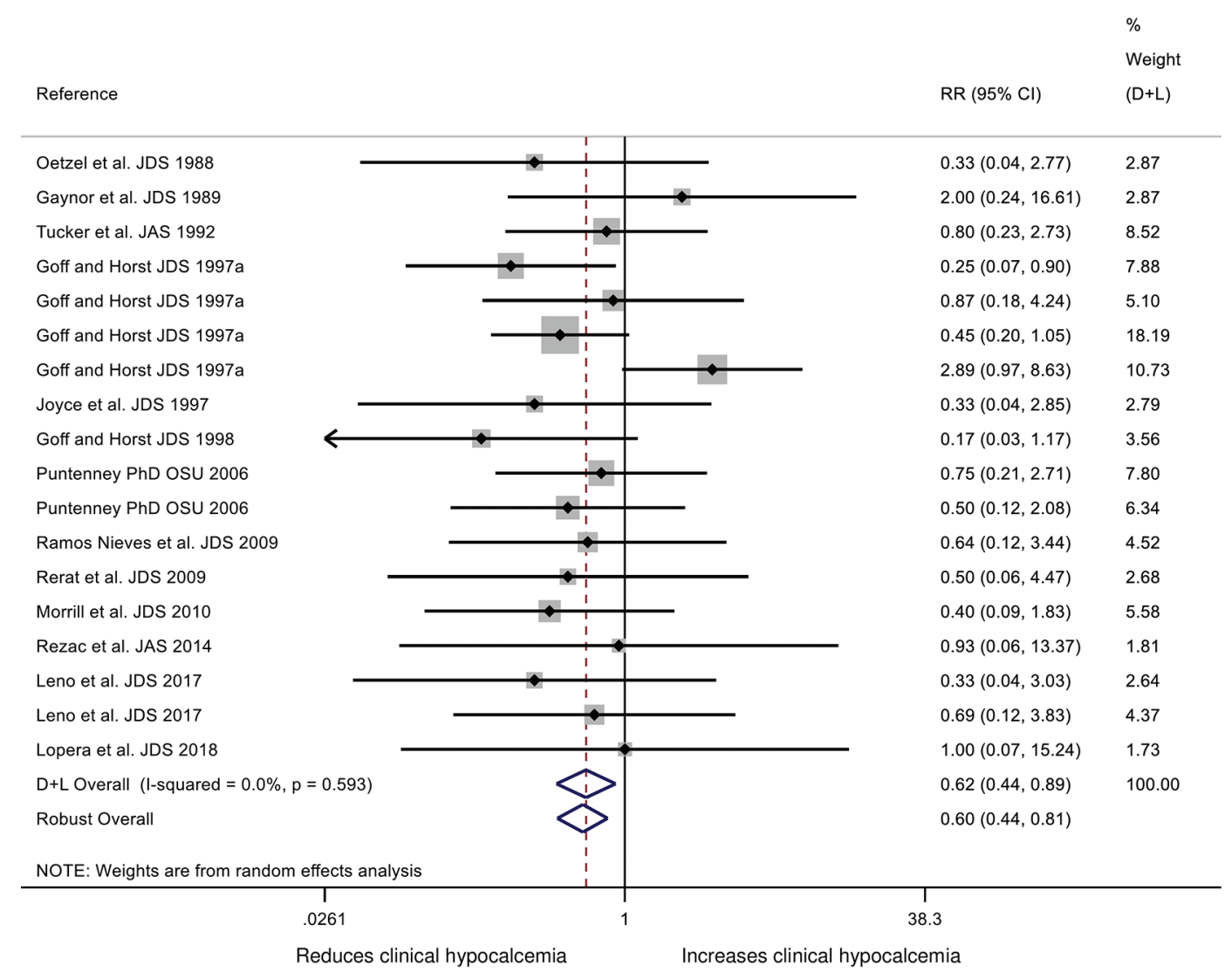

Figure 7. Forest plot of the effect size or standardized mean difference (SMD; standardized using the z-statistic) and 95\% CI of the effect of a lowered DCAD intake $(\mathrm{Eq} / \mathrm{d})$ on risk of clinical hypocalcemia in parous and nulliparous dairy cows. The solid vertical line represents a mean difference of zero or no effect. Points to the left of the line represent a reduction in risk of clinical hypocalcemia, whereas points to the right of the line indicate an increase. Each box around the point effect represents the mean effect size for that comparison and reflects the relative weighting of the comparison to the overall effect size estimate. The larger the box, the greater the comparison contribution to the overall estimate. The weight that each comparison contributed is in the right-hand column. The upper and lower limit of the line connected to the square represents the upper and lower 95\% CI for the effect size. The overall pooled effects size or SMD and 95\% CI pooled using the DerSimonian and Laird (D+L; DerSimonian and Laird, 1986) and robust meta-analytical models (Hedges et al., 2010) methods for random effects models are indicated by the respective diamonds at the bottom. The heterogeneity measure, $I^{2}$, is a measure of variation beyond chance among treatments included in the meta-analysis. The effect of a lower DCAD intake on the risk of clinical hypocalcemia was not heterogeneous, as indicated by the $I^{2}$ of $0 \%$.

a summary of the DCAD using classical meta-analysis methods for production variables including DMI, BW, and BCS measures prepartum. The differences in DCAD between the treated and control groups were greater than $-223 \mathrm{mEq} / \mathrm{kg}$ (Table 4), indicating a marked difference in DCAD. Cows fed the lower DCAD diets had reduced $(P<0.001)$ DMI $(\mathrm{SMD}=0.23$; $\mathrm{WMD}=0.29 \mathrm{~kg} / \mathrm{d})$ and lighter $(P<0.01) \mathrm{BW}$ prepartum, a reduction of $5.4 \mathrm{~kg}(\mathrm{SMD}=0.26$; Table 4$)$, compared with cows in the control group. Treatment did not affect BCS, although the negative estimated effect is consistent with the observed smaller BW in cows in the treated than control group. We observed no multivariable models that explained the observed differences in prepartum performance; however, DMI was not formally investigated because DCAD intake
$(\mathrm{Eq} / \mathrm{d})$ was a function of prepartum DMI and a few experiments limited DMI prepartum.

\section{Urine $\mathrm{pH}$}

Urinary $\mathrm{pH}$ was markedly reduced for the treated cows, with a $\mathrm{pH}$ difference of -1.226 for cows fed diets that differed by $240 \mathrm{mEq} / \mathrm{kg}$ in DCAD. The robust regression analysis SMD was -1.90 , indicating that the treated cows had a DCAD 1.90 standard deviations less than the cows in the control groups (Table 4; $P<$ 0.001). Figure 2 shows the forest plot of the effect of lowering the DCAD on urinary $\mathrm{pH}$ by treatment comparison. No multivariable model examined explained differences in response to DCAD treatment for urinary $\mathrm{pH}$; hence, no model is reported. 


\section{Postpartum DMI, BW, and BCS}

The treated groups for all these measures had DCAD that differed by more than $220 \mathrm{mEq} / \mathrm{kg}$ of DM lower than the controls. The DMI was reported in 41 comparisons within 20 experiments (Table 4). Notwithstanding a reduced DMI $(-0.288 \mathrm{~kg} / \mathrm{d})$ prepartum in treated cows, DMI tended $(P=0.06)$ to increase by $0.627 \mathrm{~kg} / \mathrm{d}$ (0.399 SMD) postpartum. The increase in postpartum DMI did not differ $(P>0.20)$ with parity group (Figure 3 ), and it was not further explained using multivariable modeling. We noted no significant difference between treated and control groups for postpartum BW or BCS. The point estimate of the SMD for nulliparous cows for

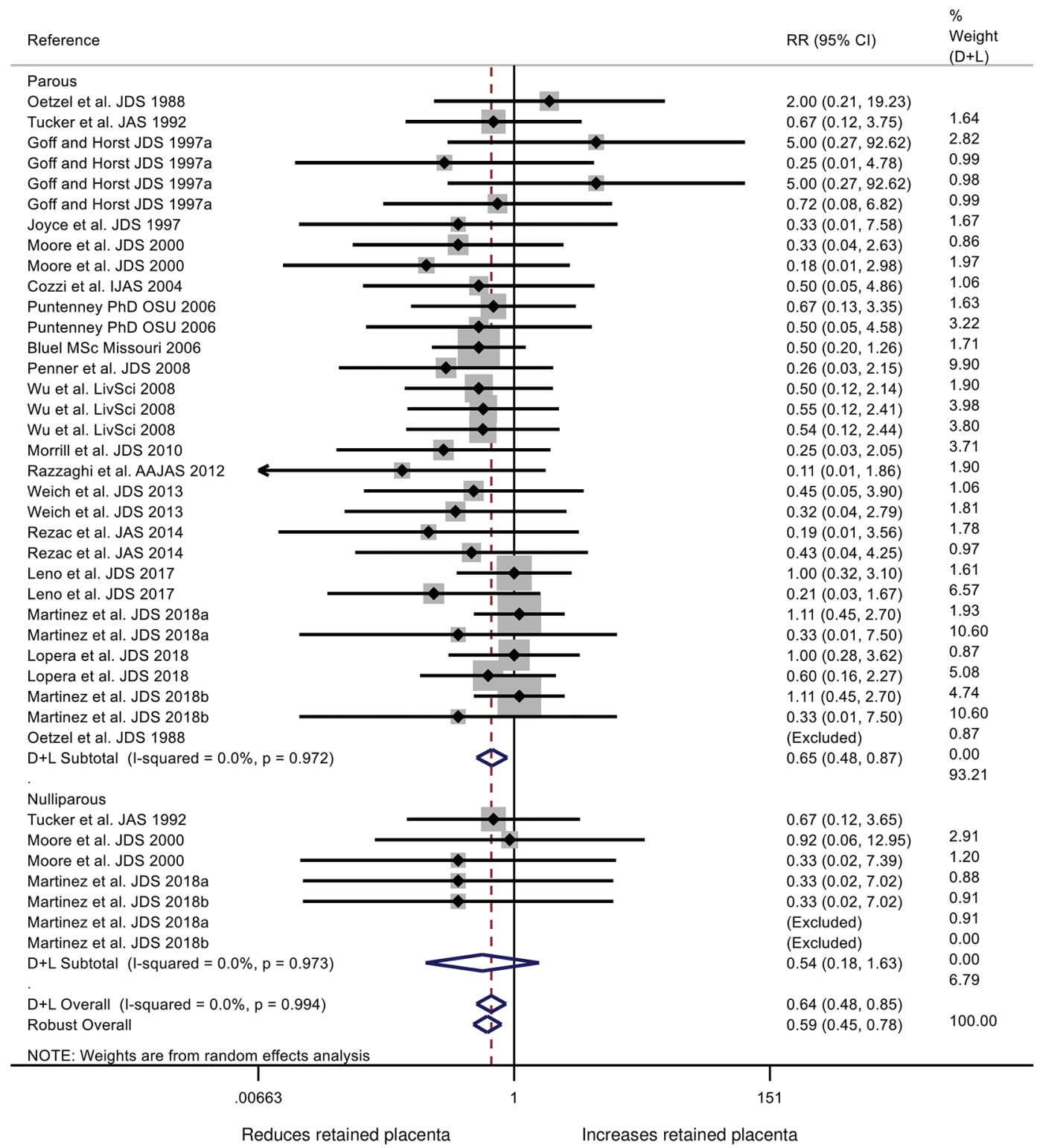

Figure 8. Forest plot of the effect size or standardized mean difference (SMD; standardized using the z-statistic) and $95 \%$ CI of the effect of a lowered DCAD intake $(\mathrm{Eq} / \mathrm{d})$ on risk of retained placenta in parous and nulliparous dairy cows. The solid vertical line represents a mean difference of zero or no effect. Points to the left of the line represent a reduction in risk of retained placenta, whereas points to the right of the line indicate an increase. Each box around the point effect represents the mean effect size for that comparison and reflects the relative weighting of the comparison to the overall effect size estimate. The larger the box, the greater the comparison contribution to the overall estimate. The weight that each comparison contributed is in the right-hand column. The upper and lower limit of the line connected to the square represents the upper and lower 95\% CI for the effect size. The overall pooled effects size or SMD and 95\% CI pooled using the DerSimonian and Laird (D+L; DerSimonian and Laird, 1986) and robust meta-analytical models (Hedges et al., 2010) methods for random effects models are indicated by the respective diamonds at the bottom. The heterogeneity measure, $I^{2}$, is a measure of variation beyond chance among treatments included in the meta-analysis. The effect of a lower DCAD intake on the risk of retained placenta was not heterogeneous, as indicated by the $I^{2}$ of $0 \%$. 
Table 3. Descriptive statistics for BW, BCS, and DMI before and after calving according to treatment group ${ }^{1}$

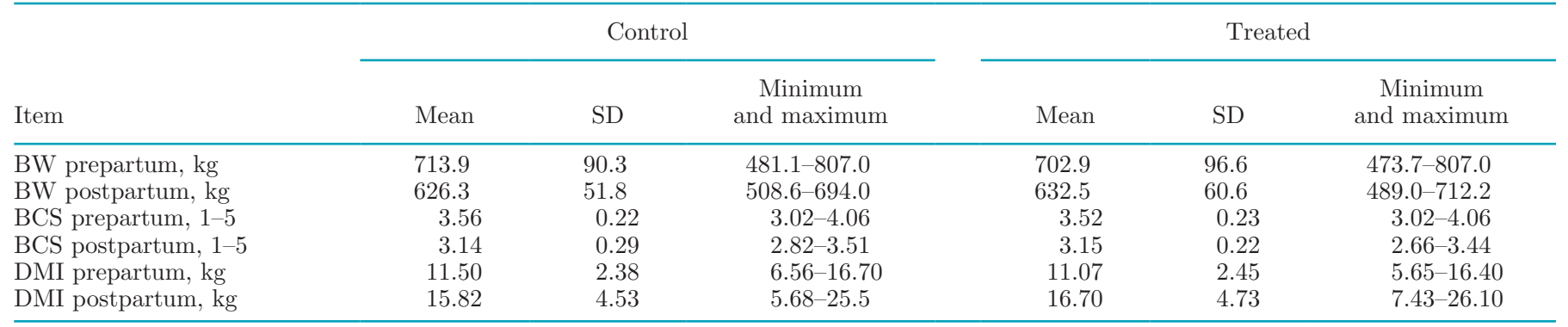

${ }^{1}$ Within each experiment, the diet with the largest DCAD value was considered the control and those with lower DCAD were considered the treated group(s).

BW after calving was lower than for parous cows (data not shown).

In the 44 comparisons and 23 experiments that evaluated milk yield, cows in treated groups produced 0.783 $\mathrm{kg} / \mathrm{d}(0.172$ SMD) more milk than cows in control groups $(P=0.05)$; however, we observed an interaction with parity (Table 4$)$ in which treatment significantly increased $(P=0.002)$ milk yield in parous cows $(1.10$ $\mathrm{kg} / \mathrm{d} ; \mathrm{ES}=0.29 ; P<0.05)$, but treated nulliparous cows tended to produce less milk than control nulliparous cows $(-1.28 \mathrm{~kg} / \mathrm{d} ; \mathrm{ES}=-0.24 ; P=0.087$; Figure 4). A positive quadratic effect of DCAD occurred at the experiment and comparison level on the SMD for milk yield (Table 4$)$. For FCM, yield increased $(P=0.03)$ by $0.558 \mathrm{~kg} / \mathrm{d}(0.118 \mathrm{SMD})$ in treated cows and, again, we observed a tendency for an interaction $(P=0.06)$ between treatment and parity group because nulliparous, treated cows produced less FCM than control, whereas parous, treated cows produced more FCM than control cows (Table 4). Appendix Figure A1 depicts the forest plot for comparisons of FCM yield between treated and control stratified by parity group. Appendix Figure A2 shows the forest plot responses for comparisons of FCM based on whether the treated group was fed a diet with negative (DCAD $<0 \mathrm{mEq} / \mathrm{kg}$ of $\mathrm{DM}$ ) or positive DCAD (DCAD $\geq 0 \mathrm{mEq} / \mathrm{kg}$ of $\mathrm{DM})$.

Treatment did not affect the overall SMD for milk fat or protein percentages (Table 4). Multivariable modeling showed that the SMD for protein percentage was increased by parity based on the interaction between treatment and parity group, reduced by differences in $\mathrm{Ca}$ intake between treated and control groups, increased with increased difference in $\mathrm{P}$ intake between the treated and control groups, and reduced with the linear and the quadratic effects of DCAD differences in intake $(\mathrm{Eq} / \mathrm{d})$ all at the comparison level. Further, an interaction between the quadratic effect of differences in $\operatorname{DCAD}(\mathrm{Eq} / \mathrm{d})$ intake and difference in $\mathrm{Ca}$ intake (g/d) between treated and control cows was found also at the comparison level (Table 4). These findings dem- onstrate that the milk protein percentage responses are mediated by differences in parity and intake of specific dietary components. Milk fat yield did not differ $(P=$ $0.40)$ with treatment $(\mathrm{WMD}=0.027 \mathrm{~kg} / \mathrm{d})$. The effect of parity on the ES was significant, as indicated by the interaction between treatment and parity group; nulliparous treated cows produced $0.08 \mathrm{~kg} / \mathrm{d}$ less milk fat yield than the nulliparous controls $(\mathrm{SMD}=0.61$ at the experiment level; $P<0.05$ ), whereas treated parous cows produced $0.05 \mathrm{~kg} / \mathrm{d}$ more milk fat than parous controls. Appendix Figure A3 shows milk fat yield stratified by parity group. The SMD for milk fat yield increased with increased difference in $\mathrm{Mg}$ intake (g/d) and increased with the linear and the quadratic effects of DCAD $(\mathrm{Eq} / \mathrm{d})$ differences in intake all at the comparison level $(P<0.05$; Table 4$)$. Milk protein yield tended $(P=0.07)$ to increase $(\mathrm{SMD}=0.207 ; 0.02$ $\mathrm{kg} / \mathrm{d}$ ) when feeding a lower DCAD, but the benefits were observed only in parous cows with an increase in protein yield $(\mathrm{WMD}=0.03 \mathrm{~kg} / \mathrm{d} ; P<0.05)$, whereas a nonsignificant decrease was noted in nulliparous cows $(\mathrm{WMD}=-0.05 \mathrm{~kg} / \mathrm{d})$. Appendix Figure A4 shows milk protein yield stratified by parity group.

\section{Concentrations of Minerals in Blood}

All comparisons of minerals in blood had differences in DCAD between treated and control groups exceeding $220 \mathrm{mEq} / \mathrm{kg}$ of DM (Table 5). Treatment did not affect blood Ca concentration before calving (Table 5). On the other hand, treated cows had increased $(P<0.001)$ blood $\mathrm{Ca}$ concentrations on the day of calving by 0.13 $\mathrm{m} M$ or 0.529 SMD (Figure 5) and after calving (0.059 $\mathrm{m} M$ or $0.364 \mathrm{SMD} ; P=0.003)$, but not in nulliparous cows compared with controls $(P<0.05)$. A multivariable model found that the SMD for Ca concentrations in blood after calving were greater in treated parous cows, had an interaction with nulliparous cows, and increased with the quadratic effect of DCAD intake $(\mathrm{mEq} / \mathrm{kg})$ at the comparison level (Table 5). 
LEAN ET AL.

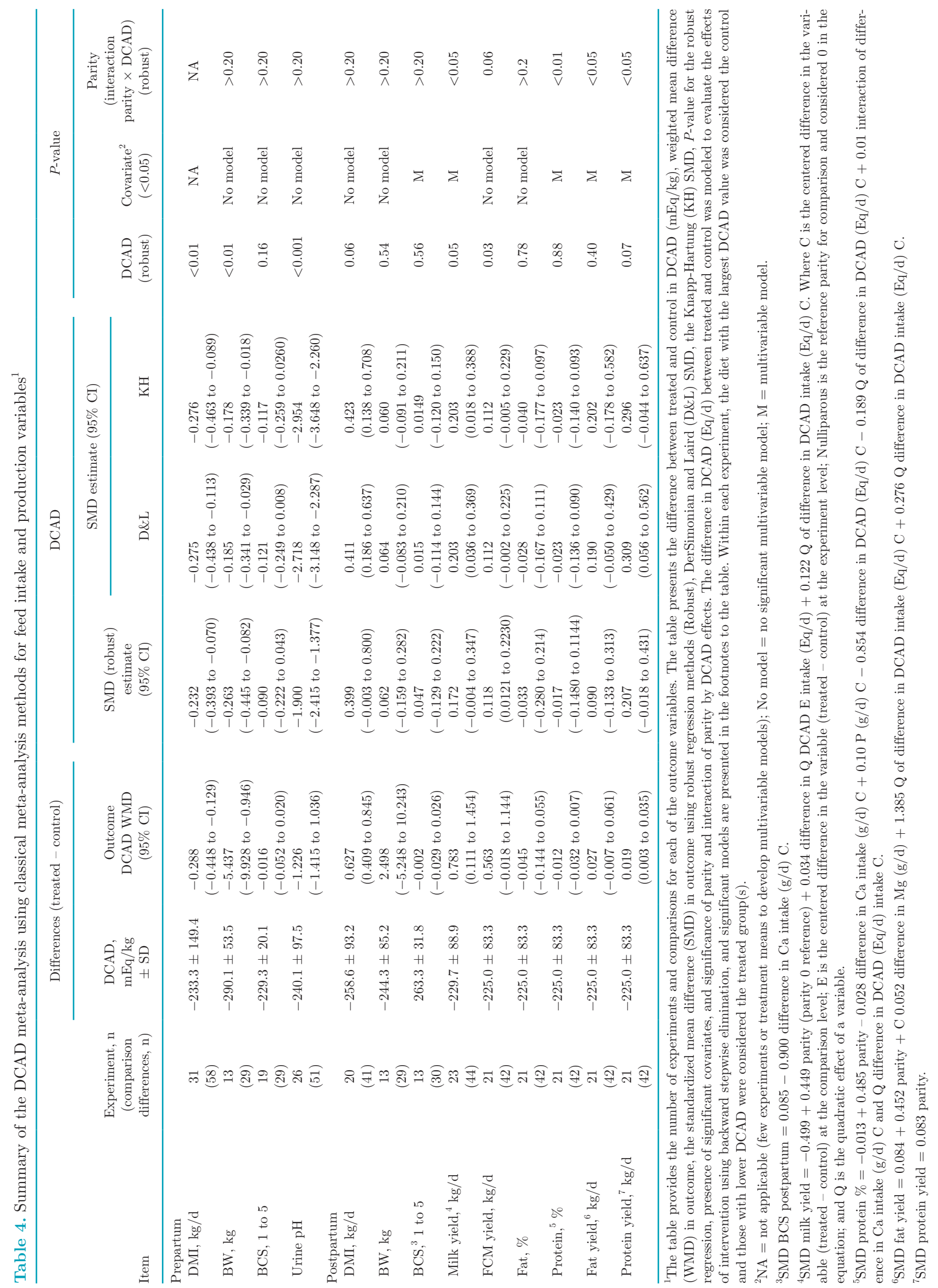


RESPONSES TO DIETARY CATION-ANION DIFFERENCE

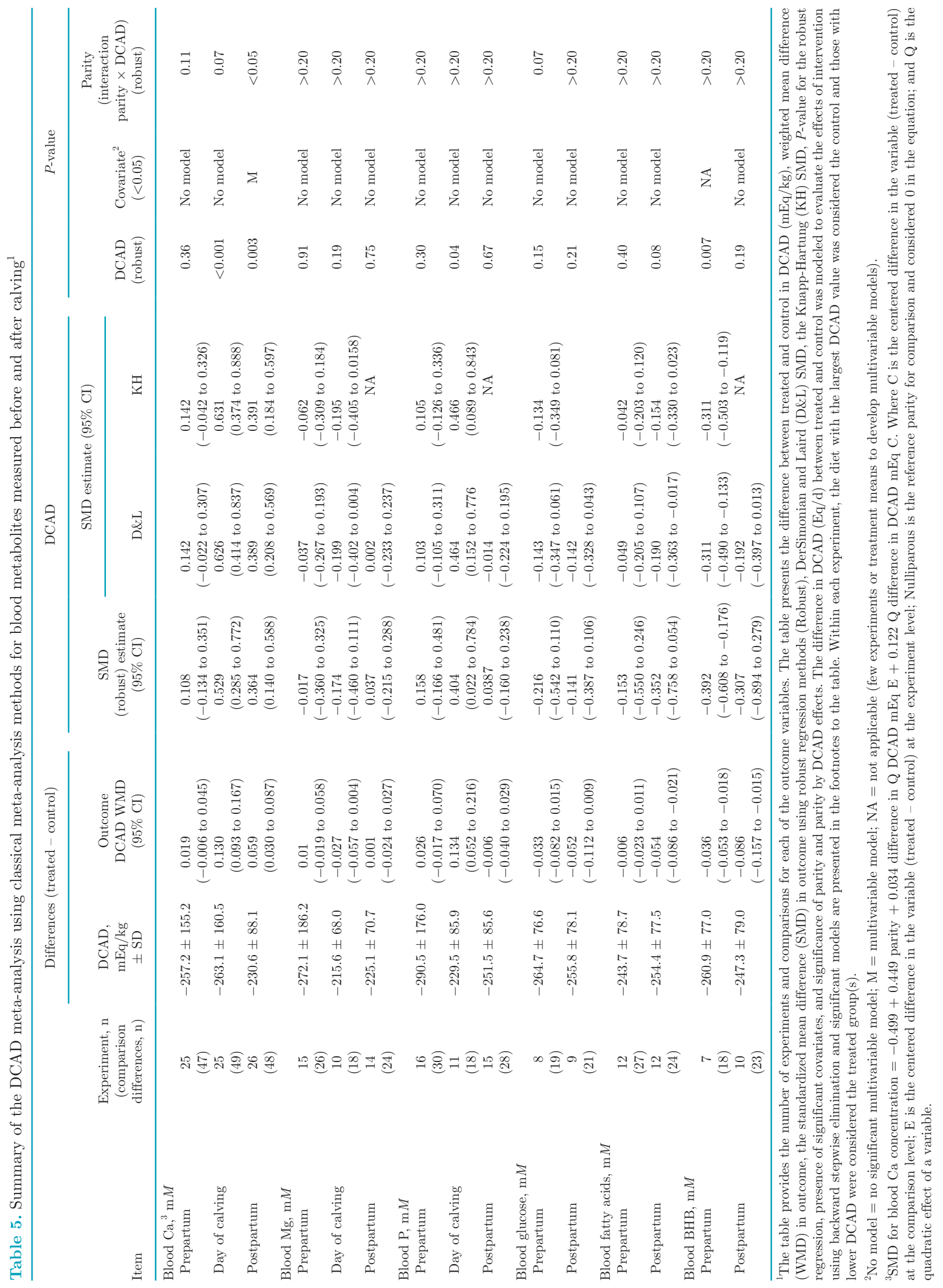


Magnesium concentrations in blood were not influenced by treatment at any of the periods evaluated (Table 5). Treatment increased $(P=0.04) \mathrm{P}$ concentrations in blood by $0.134 \mathrm{mM}(\mathrm{SMD}=0.40$; Table 5 and Figure 6 ) on the day of calving only. No multivariable models were built for the concentrations of $\mathrm{Mg}$ or $\mathrm{P}$ in blood, indicating that differences in intake of DCAD, $\mathrm{Ca}, \mathrm{P}$, and $\mathrm{Mg}$ between treated and control groups did not influence these concentrations.

\section{Concentrations of Blood Metabolites}

All comparisons of blood metabolites had differences in DCAD exceeding $220 \mathrm{mEq} / \mathrm{kg}$ of DM between treated and control groups (Table 5). However, few experiments and comparisons were available, a minimum of 7 and 18 and a maximum of 12 and 27, respectively, for meta-analytical evaluation compared with the 44 comparisons available for milk yield. We found no significant effect of treatment on blood glucose concentrations. Treated cows tended $(P=0.08$; Table 5) to have smaller fatty acid concentrations postpartum than control cows. Blood concentrations of BHB prepartum were reduced $(P=0.007)$ by $0.036 \mathrm{~m} M$ (SMD $=-0.392$ ) in treated rather than control cows (Table $5)$, but no difference between treatments were observed postpartum.

\section{Incidence of Diseases}

All comparisons for disease events had differences in DCAD exceeding $205 \mathrm{mEq} / \mathrm{kg}$ of DM between treated and control (Table 6). The incidence of clinical hypocalcemia was markedly reduced $(P<0.001)$, with a risk ratio $(\mathrm{RR})$ of 0.60 for the effect of treatment (Table 6; Figure 7$)$ and a similar reduction $(\mathrm{RR}=0.59)$ in risk of retained placenta (Table 6, Figure 8). Appendix Figure A5 shows the funnel plot for retained placenta. For the purposes of sensitivity analysis, a more conservative estimate of the effect of the lower DCAD on clinical hypocalcemia risk was derived when 1 was added to each of the cells of all comparisons, including nulliparous comparisons, that contained a zero incidence of clinical hypocalcemia and that allowed these comparisons to be used. In this case, the estimated risk reduction was $32 \%(P=0.07)$. The risk of clinical hypocalcemia increased $(P=0.03)$ with increased difference in intake of $\mathrm{P}$ between treated and control groups, and the risk of retained placenta decreased $(P=0.03)$ with increased difference in intake $\mathrm{Mg}$ intake between treated and control groups at the comparison levels. An odds ratio of 0.46 reduction $(P=0.01)$ in the risk of metritis was identified (Table 6); however, we noted no reduction in odds of mastitis or displaced abomasum (Table 6).
The risk of disease events per 100 cows decreased $(P<$ 0.01 ) by an odds ratio of 0.61 in treated compared with control cows (Table 6).

\section{DISCUSSION}

The present meta-analysis contains fewer observations than either Charbonneau et al. (2006), Lean et al. (2006), or a companion study (Santos et al., 2019). In addition, of the 15 experiments and 34 comparisons used to evaluate milk production responses to lowerDCAD diets fed before calving in the review of Lean et al. (2014), 5 experiments and 11 comparisons were not included in the evidence base for the current study. The fewer number of experiments represent the need for DMI to be reported in the source papers compared with Lean et al. $(2006 ; 2014)$ and the requirement for a treated and a control group, as compared with Charbonneau et al. (2006) and Santos et al. (2019); the latter studies used data from experiments that did not require a difference in DCAD. Further, we noted an effect of constraining studies to those evaluating DMI and DCAD as a primary treatment, as most individual experiments have limited cow numbers, ensuring that few of these studies have sufficient study power to examine differences in health outcomes without substantial type II statistical error. Our study had 1,571 cows represented in the 58 comparisons between treated and controls from 31 experiments. These provide study power and are an important consideration determining the need for meta-analytical studies of disease outcomes and the opportunity to examine some of the hypotheses, particularly in regard to disease with adequate study power, highlighting the novelty of some of the findings in our paper.

We noted a small but significant difference in BW for the groups before calving, with treated cows weighing $5 \mathrm{~kg}$ less than controls. Treated cows had less DMI prepartum, which might explain the small reduction in BW prepartum, either because of less BW gain or increased BW loss. It is possible, therefore, that the difference in BW may reflect less rumen fill associated with less DMI as well as, or independent of, an effect on body tissue mass. An effect of a diet with negative DCAD is to depress DMI, as demonstrated by Charbonneau et al. (2006), Santos et al. (2019), and Zimpel et al. (2018), which was also observed in the current study. As anticipated, urinary $\mathrm{pH}$ reduced by $1.226 \mathrm{U}$ in the treated cows, reflecting the metabolic acidification resulting from the strong ion differences of the treatments.

Milk yield increased in treated parous cows by 1.10 $\mathrm{kg} / \mathrm{d}$, but the reduction in DCAD in treated nulliparous cows reduced milk yield by $1.28 \mathrm{~kg} / \mathrm{d}$, a finding 
RESPONSES TO DIETARY CATION-ANION DIFFERENCE

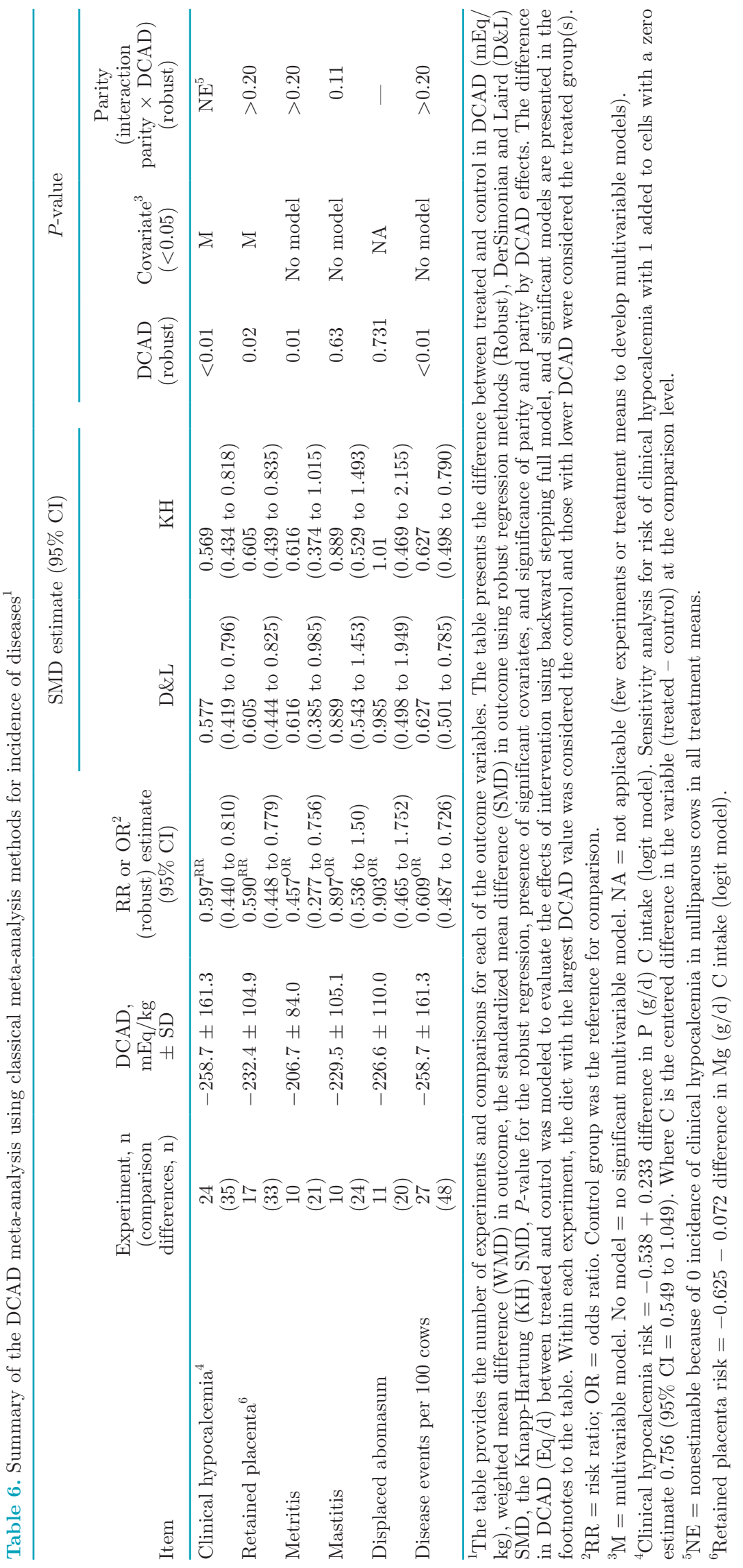

Journal of Dairy Science Vol. 102 No. 3, 2019 
consistent with Lean et al. (2014). Further, the effect of parity on the SMD for milk yield was significant in the multivariable model, indicating an interaction between treatment and parity group on milk yield. The analysis of Lean et al. (2014) did not consider potential confounding from other dietary factors in detail, and the current experiment identified that the quadratic effects of DCAD (Eq/d) intake at the experiment and treatment level influenced milk production. The yield response in parous cows is explained by the increase in DMI of $0.627 \mathrm{~kg} / \mathrm{d}$ on an energetic basis and assuming an energy density of approximately $1.74 \mathrm{Mcal}$ of $\mathrm{NE}_{1} /$ $\mathrm{kg}$ of DM (11 MJ of ME/ $\mathrm{kg}$ of DM) fed after calving. The physiological basis for this increase in DMI and subsequent milk yield is unclear but may reflect previously identified differences in physiological responses to lactation between nulliparous and parous cows. Differences in Ca metabolism between nulliparous and parous cows include greater milk yield and loss of $\mathrm{Ca}$ in colostrum for parous than nulliparous cows, 16.9 vs. $25.5 \mathrm{~g} / \mathrm{d}$, respectively (Rodney et al., 2018a), a greater demand for Ca deposition in bone for nulliparous cows (as they are still growing; NRC, 2001), and decreased sensitivity of vitamin $\mathrm{D}$ receptors in bone to vitamin D with increased age (Horst et al., 1990). However, Liesegang et al. (2008) found no decrease in vitamin $\mathrm{D}$ receptor protein expression in the tract of Brown Swiss and Holstein cows aged up to 6 yr old, suggesting that enteric tract active uptake may not be limiting for younger cows. Some of these factors may increase the risk of hypocalcemia in parous cows and, in turn, the possibility of milk loss associated with hypocalcemia and disease. We found no cases of clinical hypocalcemia in nulliparous cows in the experiments used for the meta-analysis, and this may explain, at least in part, the difference in milk yield response for parous and nulliparous cows. However, the increased DMI for the nulliparous treated cows suggests that these additional nutrients were directed toward BW rather than milk yield. The lack of difference in BW in the treated nulliparous cows after calving likely reflects a lack of precision for measurement of weight change and the limited statistical power to detect this effect. It should be noted that the point estimate for nulliparous cows for BW after calving was lower than for parous cows (data not shown). Given the limited number of experiments $(\mathrm{n}=5)$ and comparisons $(\mathrm{n}=9)$ and apparent differences in response to parous cows, further studies specifically directed at understanding responses of nulliparous cows to precalving dietary interventions related to DCAD are needed.

Although treatment did not affect milk fat percentage, a multivariable model was identified for protein percentage. The SMD for milk protein percentage in- creased with parity, indicating an interaction of parity with DCAD intake for milk protein percentage, and was notably influenced by quadratic effects of differences in DCAD (Eq/d) intake at the experiment and comparison level. Milk protein percentage is most substantially influenced by rumen fermentable energy intake; however, more anabolic influences in precalving diets may reduce milk protein percentage but increase milk yield (Rodney et al., 2016), indicating that dietary differences in the immediate prepartum can influence milk protein percentages after calving. It is also notable that an activated immune system uses glucose, approximately $1 \mathrm{~kg}$ in $720 \mathrm{~min}$ (Kvidera et al., 2017), and the differences in disease risk between treated and control groups could also account for effects on milk and milk protein yield. The difference in milk protein responses to treatment according to parity may reflect differences in partitioning of the additional DMI postpartum observed in treated cows. As expected, milk protein yield increased with treatment in parous cows, reflecting both increased milk and milk protein percentage; however, it decreased with treatment in nulliparous cows. Milk fat yield was affected by the interaction between treatment and parity, with an increase in treated parous cows compared with controls, but a decrease in treated nulliparous cows compared with controls. However, the SMD for fat yield increased by the linear and quadratic effects of the difference in DCAD (Eq/d) intake and increased with the difference in $\mathrm{Mg}$ intake $(\mathrm{g} / \mathrm{d})$ between treated and control cows, all at the comparison level. Estimates of milk fat response to treatment with the different meta-analytical models varied from significant to not significant (Table 4), and the presence of a linear and quadratic increase in milk fat SMD with increased difference in DCAD intake $(\mathrm{Eq} / \mathrm{d})$ in the multivariable models is unsurprising given the increase in milk yield with treatment and potential for a dilution of milk fat produced. Similarly, we found consistent evidence of an interaction of parity with DCAD intake difference across milk, milk fat, and protein, suggesting that the benefit of diets with lower DCAD on productive performance in our study was present in parous cows but not in nulliparous cows. The increase in milk fat yield with the difference in $\mathrm{Mg}$ intake $(\mathrm{g} / \mathrm{d})$ between treated and control cows is not clear, but might be related to effects of supplemental dietary $\mathrm{Mg}$ in lactating cows. Such responses would be consistent with Thomas and Emery (1969) and Kennelly et al. (1999), who found milk fat increases with $\mathrm{MgO}$ use, and Moate et al. (2008), who found increased preformed fatty acid production with low levels of $\mathrm{MgO}$ inclusion in the diet. Magnesium is an essential component of triacylglycerol synthesis (Coleman and Lee, 2004). However, these effects of $\mathrm{Mg}$ on milk fat were reported for lactating cow diets, not 
precalving, suggesting that $\mathrm{Mg}$ may increase milk fat yield by other means.

Numerous individual experiments found that blood total Ca concentrations at the time of calving increased in cows fed diets with lowered DCAD, and this finding is strongly supported by our meta-analysis (Figure 5; Table 5) indicating improved $\mathrm{Ca}$ metabolism in treated cows. The benefits of a diet with reduced DCAD fed before calving are evident in the increased total $\mathrm{Ca}$ in blood after calving (Table 5). The actions of a reduction in DCAD in diets fed prepartum have been reviewed (DeGaris and Lean, 2008; Goff, 2008) and include increased sensitivity of cows to parathyroid hormone (PTH; Goff et al., 2014); increased renal production of $1,25(\mathrm{OH})_{2}$ vitamin $\mathrm{D}_{3}$ (Gaynor et al., 1989; Goff et al., 1991); increased responsiveness of target tissues to $1,25(\mathrm{OH})_{2}$ vitamin $\mathrm{D}_{3}$ associated with increased gastrointestinal Ca absorption (Wilkens et al., 2016); increased resorption of Ca from bone (Block, 1984; Goff and Horst, 1997b; Leclerc and Block, 1989); and increased plasma ionized Ca concentrations (Oetzel et al., 1991; Rodney et al., 2018a). The finding that P concentrations in blood increased on the day of calving is consistent with several of the individual studies that had significant increases in blood $\mathrm{P}$ concentrations at calving (Figure 6). Bone $\mathrm{P}$ resorption is influenced by PTH activity, blood concentrations of $\mathrm{Ca}$ and $\mathrm{P}$ (Hill et al., 2008), and by $1,25(\mathrm{OH})_{2}$ vitamin $\mathrm{D}_{3}$. If increased bone resorption is stimulated by the diets with lower DCAD, it is likely that $\mathrm{P}$ concentrations in the blood would increase along with Ca concentrations. However, other mechanisms, such as a likely increased absorption of $\mathrm{P}$ in the gastrointestinal tract, could contribute to the increased $\mathrm{P}$ concentrations.

The changes in concentrations of blood glucose, fatty acids, and BHB are interesting to evaluate, as DeGaris et al. (2010) found substantial differences in the concentrations of BHB that increased both pre- and postpartum with additional days receiving prepartum diets that had negative DCAD. The lack of marked response in concentrations of energy metabolites in our study suggests that changes observed by DeGaris et al. (2010) were more a reflection of intake of other nutrients than an effect of the DCAD content of the diet. We noted less disease and greater DMI in treated cows in the current study. Avoiding disease and increased DMI should lower BHB concentrations. Notwithstanding that observation, it is clear that reducing DCAD, or increasing intake of strong anions, can influence energy metabolism through altered Ca status. Martinez et al. (2014) induced subclinical hypocalcemia in dry cows and found smaller DMI, greater blood glucose and fatty acid concentrations, and smaller concentrations of insulin in cows induced to develop subclinical hypocalcemia compared with cows that received intravenous saline solution. Capen and Rosol (1989) found that physiological concentrations of $\mathrm{Ca}$ in blood may be required for glucose to stimulate insulin release from pancreatic $\beta$-cells. Lean et al. (2014) identified positive and negative associations between concentrations of blood $\mathrm{Ca}$ and fatty acids, glucose, and BHB over time in cows fed a diet with negative DCAD. Further, strong positive associations between blood calcidiol and indicators of energy metabolism, including glucose, fatty acids, and BHB, were identified using time series methods (Rodney et al., 2018b). The combined effects of reduced disease incidence and prevalence, increased DMI, and adaptations in metabolism likely explain the reduction in BHB.

We noted very marked reductions in clinical hypocalcemia $(\mathrm{RR}=0.60$ reduction in risk or $32 \%$ in sensitivity analysis), retained placenta $(\mathrm{RR}=0.59$ reduction in risk), metritis [odds ratio $(\mathbf{O R})=0.46$ reduction in odds] and overall disease $(\mathrm{OR}=0.61)$. These findings reflect consistent nonsignificant reductions in risk for clinical hypocalcemia and retained placenta in individual studies (Figures 7 and 8) and previous studies showing that reducing DCAD in the prepartum diet reduces the risk of clinical hypocalcemia (Oetzel, 1991; Charbonneau et al., 2006; Lean et al., 2006). All metaanalyses published on the effects of DCAD on milk fever have relied on the definitions published in the source publications, and it is probable that effects on clinical hypocalcemia would differ depending on precise outcomes of interest (i.e., recumbency, early clinical signs of hypocalcemia, or definitions based on blood calcium concentrations). Only differences in $\mathrm{P}$ intake (g/d) between treated and controls were significant in predicting clinical hypocalcemia risk and supported previous findings that increased $\mathrm{P}$ concentrations in prepartum diets increased clinical hypocalcemia risk (Lean et al., 2006). However, neither differences in Ca or $\mathrm{Mg}$ intake (g/d) influenced the risk of clinical hypocalcemia, in contrast to earlier findings (Oetzel, 1991; Lean et al., 2006) based on concentrations of $\mathrm{Ca}$ and $\mathrm{P}$ in the diet. The experiments included in the meta-analyses also differ among Oetzel (1991), Lean et al. (2006), Santos et al. (2019), and the current meta-analysis, as do the statistical methods. Santos et al. (2019), using a larger database, found no effect of dietary $\mathrm{Mg}$ content and a tendency for dietary Ca content to increase the risk of clinical hypocalcemia. We observed considerable consistency of the earlier meta-analyses evaluating the effects of Ca concentrations in the diet (Lean et al., 2009), with Oetzel (1991), Enevoldsen (1993), and Lean et al. (2006) all finding similar estimates for a quadratic effect of $\mathrm{Ca}$ concentrations in the diet on the risk of clinical hypocalcemia. The quadratic effect of dietary 
Ca concentration on clinical hypocalcemia risk is consistent with a biological model that has increased release of PTH and, consequently, 1,25-dihydroxyvitamin $\mathrm{D}_{3}$ with a low $\mathrm{Ca}$ intake (Goings et al., 1974; Green et al., 1981) and probable paracellular uptake of Ca across the gastrointestinal tract (Hoenderop et al., 2005; Hyde and Fraser, 2014) with increased Ca concentrations that may both reduce the risk of clinical hypocalcemia; however, intermediate concentrations of $\mathrm{Ca}$ in $\mathrm{DM}$ of prepartum diets may increase risk. On balance, a strategy of feeding sufficient Ca seems prudent to allow $\mathrm{Ca}$ balance to be maintained when calciuria stimulated by feeding a negative DCAD diet occurs before calving; we found no identifiable benefit of providing amounts of $\mathrm{Ca}$ in the diet exceeding this amount. Rodney et al. (2018a) fed approximately $63 \mathrm{~g} / \mathrm{d}$ of $\mathrm{Ca}(0.55 \%$ of DM as $\mathrm{Ca}$ ) to cows that maintained an estimated positive Ca balance of more than $10 \mathrm{~g} / \mathrm{d}$ when fed diet DCAD less than $-120 \mathrm{mEq} / \mathrm{kg}$.

Despite no effect of difference in $\mathrm{Mg}$ intake $(\mathrm{g} / \mathrm{d}$ ) between treated and control groups on clinical hypocalcemia, the increased difference in $\mathrm{Mg}$ intake $(\mathrm{g} / \mathrm{d})$ reduced the risk of retained placenta. It is unclear why differences in $\mathrm{Mg}$ intake $(\mathrm{g} / \mathrm{d})$ between treated and control groups did not influence clinical hypocalcemia risk given evidence that $\mathrm{Mg}$ is important in PTH release (Rayssiguier et al., 1977), that increased intake of $\mathrm{Mg}$ tended to reduce urinary excretion of $\mathrm{Ca}$ (Wang and Beede, 1992), that hypomagnesemic cows are less responsive to PTH (Sansom et al., 1983; Goff, 2000), and the strong association between $\mathrm{Mg}$ and risk of clinical hypocalcemia in the meta-analysis by Lean et al. (2006). We found no evidence of an adverse effect of increasing $\mathrm{Mg}$ intake on clinical hypocalcemia, and, given that increased $\mathrm{Mg}$ intake decreased the relative risk of retained placenta, we consider that a recommendation of 0.40 to $0.45 \% \mathrm{Mg}$ in the diet can be sustained based on the values suggested by others (Lean et al., 2006; Goff, 2008).

The magnitude of reduction in odds of metritis (OR $=0.46)$ with a reduction in DCAD was large. A reduction in DCAD increased concentrations of Ca at calving and postpartum and reduced the risk of clinical hypocalcemia. Ample evidence exists that hypocalcemic cows have increased risk of metritis (Curtis et al., 1983; Borsberry and Dobson, 1989; Martinez et al., 2012), and these data provide strong support for a role of Ca metabolism in both the pathogenesis of retained placenta and metritis.

We found no evidence that reducing DCAD influenced the risks of mastitis or abomasal displacement. There is physiological support for a role of hypocalcemia in both conditions; however, neither condition was universally reported and more studies reporting these outcomes would be of benefit to provide additional study power. Reducing the DCAD, which resulted in a decline in DCAD of more than $200 \mathrm{mEq} / \mathrm{kg}$ and a differential DCAD intake of $2.92 \mathrm{Eq} / \mathrm{d}$, reduced the odds of overall diseases by $39 \%$ (OR $=0.61)$ compared with cows fed the control diets.

Quite marked differences exist in the database and analytical methods used for our study to that used by Lean et al. (2006). The current meta-analysis has 24 experiments and 35 comparisons (Table 1) and 1,571 cows. Lean et al. (2006) used 35 experiments and 2,545 cows, and many of those experiments lacked DMI prepartum, whereas such experiments were not considered for the current meta-analysis. Notwithstanding, the current meta-analysis included 13 new experiments that had clinical hypocalcemia and other responses. The analytical methods used in the current meta-analysis (i.e., robust meta-regression) account for the effects of comparison and experiment and are more conservative than the DerSimonian and Laird or KnappHartung models (Hedges et al., 2010). Consequently, the evidence base of the current study is smaller and less statistically powerful, but more rigorous. Only 11 experiments were used in both Lean et al. (2006) and the current meta-analysis and, of these, 2 experiments did not have incidence of clinical hypocalcemia. Figures $9 \mathrm{~A}$ and $\mathrm{B}$ show that although differences in Ca percentage and intake were substantial between treatments, there was less obvious difference in $\mathrm{Mg}$ percentage in the diet and intake (Figure 10A and B). The differences in Ca percentage and intake indicate some confounding in study designs that allowed a change in variables other than changes in DCAD intake. This confounding provided the potential to evaluate the effect of $\mathrm{Ca}$ on the response. Given the differences in study design in the experiments used in our study, the distribution of the $\mathrm{Ca}$ and $\mathrm{Mg}$ data and the more limited study power in regard to evaluating differences in $\mathrm{Ca}$ and $\mathrm{Mg}$ percentage and intake in the diet, the previous findings in regard to the effects of $\mathrm{Ca}$ and $\mathrm{Mg}$ in the diet on clinical hypocalcemia risk (Lean et al., 2006) still have relevance. The effects of $\mathrm{Mg}$ in reducing risk retained placenta are important considerations in maintaining $\mathrm{Mg}$ intake.

\section{CONCLUSIONS}

This study provides strong support for feeding prepartum diets with lower DCAD, which resulted in more than $200 \mathrm{mEq} / \mathrm{kg}$ smaller DCAD than control diets and improved yields of milk, FCM, and protein in parous cows. Further, feeding diets with lower DCAD increased $\mathrm{Ca}$ and $\mathrm{P}$ concentrations in blood on the day of calving as well as Ca concentrations after calving. 
OPre 2006

- Post 2006
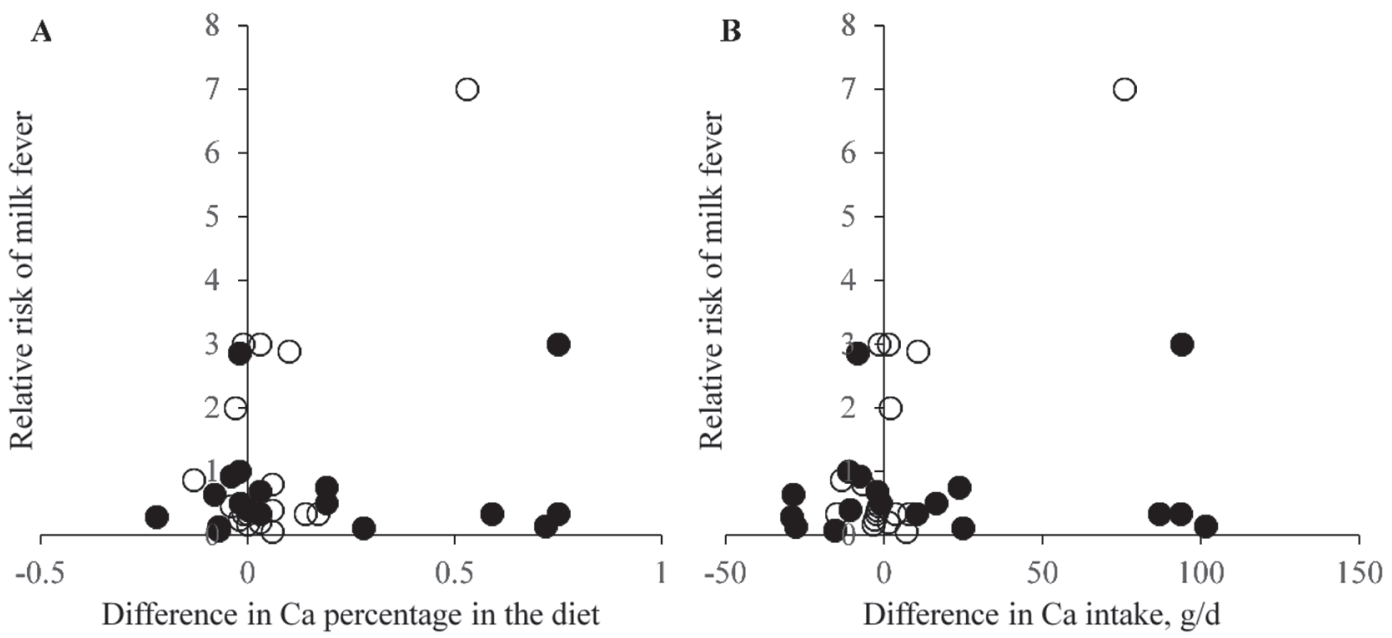

Figure 9. Difference in Ca percentage in the diet (A) and difference in Ca intake g/d (B) by experiments before 2006 and after 2006.

The lower-DCAD diets markedly reduced the risks of clinical hypocalcemia, retained placenta, metritis, and overall disease in the periparturient period. There was no evidence to support a particular level of Ca intake. We noted a positive role for increased $\mathrm{Mg}$ intake in increased milk fat yield and in reducing the risk of retained placenta. The potential for increased prepartum $\mathrm{P}$ intake to increase risk of clinical hypocalcemia was supported. Parity responses to treatment differed, particularly for milk yield, in that nulliparous cows fed a lower-DCAD diet prepartum had a lower milk yield by $1.28 \mathrm{~kg} / \mathrm{d}$, whereas parous cows increased yield by $1.1 \mathrm{~kg} / \mathrm{d}$. There was no evidence that the difference in yield response between parity groups reflected a partitioning of energy intake to body tissue in nulliparous cows. Collectively, results demonstrated that parous cows benefit from diets with lower DCAD intake by improving health and lactation performance. Nevertheless, studies are needed to evaluate the optimal $\mathrm{Ca}$ and $\mathrm{Mg}$ concentrations in prepartum diets. Likewise, further experiments are needed to determine the optimal prepartum DCAD for nulliparous cows, especially given

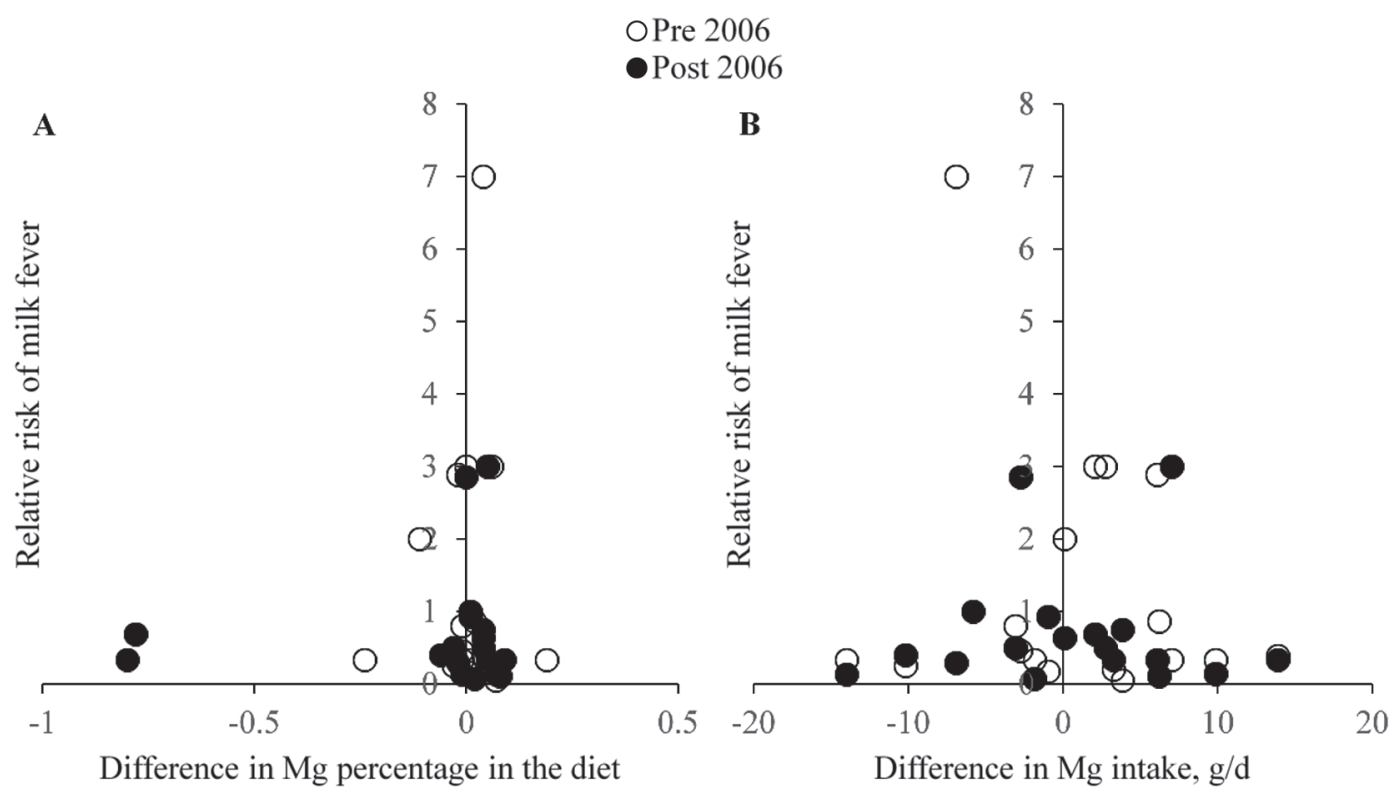

Figure 10. Difference in $\mathrm{Mg}$ percentage in the diet (A) and difference in $\mathrm{Mg}$ intake $\mathrm{g} / \mathrm{d}$ (B) by experiments before 2006 and after 2006. 
the limited number of studies available for analyses of this effect, to understand why diets with lower DCAD improved health but depressed yields of milk and milk components in nulliparous cows. In particular, future research should emphasize recording weight and nutrient balance in parous cows in comparison to nulliparous cows to evaluate whether nutrient partitioning may differ between these groups when exposed to lower-DCAD diets.

\section{REFERENCES}

Block, E. 1984. Manipulating dietary anions and cations for prepartum dairy cows to reduce incidence of milk fever. J. Dairy Sci. 67:2939-2948.

Bluel, R. J. V. 2006. The effects of supplemental anionic salts and yeast culture on the production of dairy cattle during the periparturient period. MS Thesis, Department of Animal Sciences, University of Missouri, Columbia. Accessed Nov. 30, 2018. https: //mospace.umsystem.edu/xmlui/bitstream/handle/10355/4638/ research.pdf? sequence $=3 \&$ is Allowed $=\mathrm{y}$.

Borenstein, M., J. P. T. Higgins, L. V. Hedges, and H. R. Rothstein. 2017. Basics of meta-analysis: I2 is not an absolute measure of heterogeneity. Res. Synth. Methods 8:5-18.

Borsberry, S., and H. Dobson. 1989. Periparturient diseases and their effect on reproductive performance in five dairy herds. Vet. Rec. 124:217-219

Capen, C. C., and T. Rosol. 1989. The calcium regulating hormones: Parathyroid hormone, calcitonin, and cholecalciferol. Vet. Endocrinol. Reprod. 3:60-130.

Charbonneau, E., D. Pellerin, and G. R. Oetzel. 2006. Impact of lowering dietary cation-anion difference in nonlactating dairy cows: A meta-analysis. J. Dairy Sci. 89:537-548.

Coleman, R. A., and D. P. Lee. 2004. Enzymes of triacylglycerol synthesis and their regulation. Prog. Lipid Res. 43:134-176.

Cozzi, G., F. Dal Corobbo, A. Pesavento, L. Ravarotto, and G. Gabai. 2005. Effects of two different prepartum diets on some metabolic traits and productive response in multiparous Holstein cows in early lactation. Ital. J. Anim. Sci. 4:127-137.

Curtis, C. R., H. Erb, C. Sniffen, R. Smith, P. Powers, M. Smith, M. White, R. Hillman, and E. Pearson. 1983. Association of parturient hypocalcemia with eight periparturient disorders in Holstein cows. J. Am. Vet. Med. Assoc. 183:559-561.

DeGaris, P. J., I. Lean, A. Rabiee, and M. Stevenson. 2010. Effects of increasing days of exposure to prepartum diets on the concentration of certain blood metabolites in dairy cows. Aust. Vet. J. $88: 137-145$.

DeGaris, P. J., and I. J. Lean. 2008. Milk fever in dairy cows: A review of pathophysiology and control principles. Vet. J. 176:58-69.

DeGroot, M. A., E. Block, and P. D. French. 2010. Effect of prepartum anionic supplementation on periparturient feed intake, health, and milk production. J. Dairy Sci. 93:5268-5279.

DerSimonian, R., and N. Laird. 1986. Meta-analysis in clinical trials Control. Clin. Trials 7:177-188.

Dishington, I. W. 1975. Prevention of milk fever (hypocalcemic paresis puerperalis) by dietary salt supplements. Acta Vet. Scand. 16:503-512.

Dohoo, I. R., S. W. Martin, and H. Stryhn. 2009. Veterinary epidemiologic research. VER, Incorporated, Charlottetown, Prince Edward Island, Canada.

Ender, F., I. W. Dishington, and A. Helgebostad. 1971. Calcium balance studies in dairy cows under experimental induction and prevention of hypocalcaemic paresis puerperalis. Z. Tierphysiol. Tierenahr. Futtermittelkd. 28:233-256.

Enevoldsen, C. 1993. Nutritional risk factors for milk fever in dairy cattle: Meta-analysis revisited. Acta Vet. Scand. Suppl. 89:131134
Ganjkhanlou, M., A. Nikkhah, and A. Zali. 2010. Effect of dietary cation-anion balance on milk production and blood mineral of Holstein cows during the last two months of pregnancy. Afr. J. Biotechnol. 9:5983-5988.

Gaynor, P. J., F. Mueller, J. Miller, N. Ramsey, J. Goff, and R. Horst. 1989. Parturient hypocalcemia in jersey cows fed alfalfa haylagebased diets with different cation to anion ratios. J. Dairy Sci. 72:2525-2531.

Goff, J. P., and R. Horst. 1997a. Effects of the addition of potassium or sodium, but not calcium, to prepartum rations on milk fever in dairy cows. J. Dairy Sci. 80:176-186.

Goff, J. P., and R. Horst. 1997b. Physiological changes at parturition and their relationship to metabolic disorders. J. Dairy Sci. 80:1260-1268

Goff, J. P., and R. Horst. 1998. Use of hydrochloric acid as a source of anions for prevention of milk fever. J. Dairy Sci. 81:2874-2880.

Goff, J. P. 2000. Pathophysiology of calcium and phosphorus disorders. Vet. Clin. North Am. Food Anim. Pract. 16:319-337.

Goff, J. P. 2008. The monitoring, prevention, and treatment of milk fever and subclinical hypocalcemia in dairy cows. Vet. J. 176:50-57.

Goff, J. P., R. L. Horst, F. J. Mueller, J. K. Miller, G. A. Kiess, and H. H. Dowlen. 1991. Addition of chloride to a prepartal diet high in cations increases 1,25 -dihydroxyvitamin $\mathrm{D}$ response to hypocalcemia preventing milk fever. J. Dairy Sci. 74:3863-3871.

Goff, J. P., A. Liesegang, and R. Horst. 2014. Diet-induced pseudohypoparathyroidism: A hypocalcemia and milk fever risk factor. J. Dairy Sci. 97:1520-1528.

Goings, R. L., N. Jacobson, D. Beitz, E. Littledike, and K. Wiggers. 1974. Prevention of parturient paresis by a prepartum, calciumdeficient diet. J. Dairy Sci. 57:1184-1188.

Golder, H. M., and I. J. Lean. 2016. A meta-analysis of lasalocid effects on rumen measures, beef and dairy performance, and carcass traits in cattle. J. Anim. Sci. 94:306-326.

Green, H. B., R. Horst, D. Beitz, and E. Littledike. 1981. Vitamin D metabolites in plasma of cows fed a prepartum low-calcium diet for prevention of parturient hypocalcemia. J. Dairy Sci. 64:217-226.

Grünberg, W., S. Donkin, and P. Constable. 2011. Periparturient effects of feeding a low dietary cation-anion difference diet on acidbase, calcium, and phosphorus homeostasis and on intravenous glucose tolerance test in high-producing dairy cows. J. Dairy Sci. 94:727-745.

Gulay, M., M. Hayen, K. Bachman, and H. Head. 2008. Prepartum feeding of cationic or anionic diets to Holstein cows given 30 or 60 day dry periods: Comparison of dry matter intake, physiological measures and milk production. Asian-Australas. J. Anim. Sci. 21:83.

Hedges, L. V., E. Tipton, and M. C. Johnson. 2010. Robust variance estimation in meta-regression with dependent effect size estimates. Res. Synth. Methods 1:39-65.

Higgins, J. P. T., and S. Green, ed. 2011. Cochrane Handbook for Systematic Reviews of Interventions. Version 5.1.0 [updated March 2011]. The Cochrane Collaboration. Accessed Nov. 30, 2018. http: //handbook.cochrane.org.

Higgins, J. P. T., and S. G. Thompson. 2002. Quantifying heterogeneity in a meta-analysis. Stat. Med. 21:1539-1558.

Hill, S. R., K. Knowlton, E. Kebreab, J. France, and M. Hanigan. 2008. A model of phosphorus digestion and metabolism in the lactating dairy cow. J. Dairy Sci. 91:2021-2032.

Hoenderop, J. G., B. Nilius, and R. J. Bindels. 2005. Calcium absorption across epithelia. Physiol. Rev. 85:373-422.

Horst, R. L., J. Goff, and T. Reinhardt. 1990. Advancing age results in reduction of intestinal and bone 1, 25-dihydroxyvitamin $\mathrm{D}$ receptor. Endocrinology 126:1053-1057.

Hyde, M. L., and D. R. Fraser. 2014. In vivo measurement of the absorption of strontium in the rumen and small intestine of sheep as an index of calcium absorption capacity. Br. J. Nutr. 112:718-724.

Joyce, P. W., W. Sanchez, and J. Goff. 1997. Effect of anionic salts in prepartum diets based on alfalfa. J. Dairy Sci. 80:2866-2875.

Kennelly, J. J., B. Robinson, and G. R. Khorasani. 1999. Influence of carbohydrate source and buffer on rumen fermentation character- 
istics, milk yield, and milk composition in early-lactation Holstein cows. J. Dairy Sci. 82:2486-2496.

Knapp, G., and J. Hartung. 2003. Improved tests for a random effects meta-regression with a single covariate. Stat. Med. 22:2693-2710.

Kocabağli, N., R. Kahraman, I. Abaş, H. Eseceli, and M. Alp. 2001. The effects of supplemental anionic salts and probiotic in prepartum diets on milk production and quality and incidence of milk fever in dairy cows. Turk. J. Vet. Anim. Sci. 25:743-751.

Kvidera, S. K., E. Horst, M. Abuajamieh, E. Mayorga, M. S. Fernandez, and L. Baumgard. 2017. Glucose requirements of an activated immune system in lactating Holstein cows. J. Dairy Sci. 100:2360-2374.

Lean, I. J., P. J. DeGaris, P. Celi, D. M. McNeill, R. M. Rodney, and D. R. Fraser. 2014. Influencing the future: Interactions of skeleton, energy, protein and calcium during late gestation and early lactation. Anim. Prod. Sci. 54:1177-1189.

Lean, I. J., P. J. DeGaris, D. M. McNeil, and E. Block. 2006. Hypocalcemia in dairy cows: Meta-analysis and dietary cation anion difference theory revisited. J. Dairy Sci. 89:669-684.

Lean, I. J., A. R. Rabiee, T. F. Duffield, and I. R. Dohoo. 2009. Invited review: Use of meta-analysis in animal health and reproduction: Methods and applications. J. Dairy Sci. 92:3545-3565.

Leclerc, H., and E. Block. 1989. Effects of reducing dietary cationanion balance for prepartum dairy cows with specific reference to hypocalcemic parturient paresis. Can. J. Anim. Sci. 69:411-423.

Lee, N. K., H. Sowa, E. Hinoi, M. Ferron, J. D. Ahn, C. Confavreux, R. Dacquin, P. J. Mee, M. D. McKee, and D. Y. Jung. 2007. Endocrine regulation of energy metabolism by the skeleton. Cell 130:456-469.

Lema, M., W. Tucker, M. Aslam, I. Shin, P. Le Ruyet, and G. Adams. 1992. Influence of calcium chloride fed prepartum on severity of edema and lactational performance of dairy heifers. J. Dairy Sci. 75:2388-2393.

Leno, B. M., C. Ryan, T. Stokol, D. Kirk, K. Zanzalari, J. Chapman, and T. Overton. 2017. Effects of prepartum dietary cation-anion difference on aspects of peripartum mineral and energy metabolism and performance of multiparous Holstein cows. J. Dairy Sci. 100:4604-4622.

Liesegang, A., K. Singer, and A. Boos. 2008. Vitamin D receptor amounts across different segments of the gastrointestinal tract in Brown Swiss and Holstein Friesian cows of different age. J. Anim. Physiol. Anim. Nutr. (Berl.) 92:316-323.

Lopera, C., R. Zimpel, A. Vieira-Neto, F. R. Lopes, W. Ortiz, B. N. Faria, M. L. Gambarini, M. Poindexter, E. Block, C. D. Nelson, and J. E. P. Santos. 2018. Effects of level of dietary cation-anion difference and duration of prepartum feeding on performance and metabolism of dairy cows. J. Dairy Sci. 101:7907-7929.

Martín-Tereso, J., H. Wijlen, H. Laar, and M. Verstegen. 2014. Peripartal calcium homoeostasis of multiparous dairy cows fed rumenprotected rice bran or a lowered dietary cation/anion balance diet before calving. J. Anim. Physiol. Anim. Nutr. (Berl.) 98:775-784.

Martinez, N., C. Risco, F. Lima, R. Bisinotto, L. Greco, E. Ribeiro, F. Maunsell, K. Galvão, and J. Santos. 2012. Evaluation of peripartal calcium status, energetic profile, and neutrophil function in dairy cows at low or high risk of developing uterine disease. J. Dairy Sci. 95:7158-7172.

Martinez, N., R. M. Rodney, E. Block, L. L. Hernandez, C. D. Nelson, I. J. Lean, and J. E. P. Santos. 2018a. Effects of prepartum dietary cation-anion difference and source of vitamin D on dairy cows: Lactation performance and energy metabolism. J. Dairy Sci. 101:2544-2562.

Martinez, N., R. M. Rodney, E. Block, L. L. Hernandez, C. D. Nelson, I. J. Lean, and J. E. P. Santos. 2018b. Effects of prepartum dietary cation-anion difference and source of vitamin D on dairy cows: Health and reproductive responses. J. Dairy Sci. 101:2563-2578.

Martinez, N., L. Sinedino, R. Bisinotto, E. Ribeiro, G. Gomes, F. Lima, L. Greco, C. Risco, K. Galvão, and D. Taylor-Rodriguez. 2014. Effect of induced subclinical hypocalcemia on physiological responses and neutrophil function in dairy cows. J. Dairy Sci. $97: 874-887$.
Moate, P. J., W. Chalupa, R. Boston, and I. Lean. 2008. Milk fatty acids II: Prediction of the production of individual fatty acids in bovine milk. J. Dairy Sci. 91:1175-1188.

Moher, D., A. Liberati, J. Tetzlaff, D. G. Altman, and P. G. The. 2009. Preferred reporting items for systematic reviews and metaanalyses: The PRISMA statement. PLoS Med. 6:e1000097.

Moore, S. J., M. VandeHaar, B. Sharma, T. Pilbeam, D. Beede, H. Bucholtz, J. Liesman, R. Horst, and J. Goff. 2000. Effects of altering dietary cation-anion difference on calcium and energy metabolism in peripartum cows. J. Dairy Sci. 83:2095-2104.

Morrill, K. M., S. Marston, N. L. Whitehouse, M. Van Amburgh, C. G. Schwab, D. Haines, and P. S. Erickson. 2010. Anionic salts in the prepartum diet and addition of sodium bicarbonate to colostrum replacer, and their effects on immunoglobulin G absorption in the neonate. J. Dairy Sci. 93:2067-2075.

NRC. 2001. Nutrient Requirements of Dairy Cattle. 7th ed. Natl. Acad. Press, Washington, DC.

Oetzel, G. R. 1991. Meta-analysis of nutritional risk factors for milk fever in dairy cattle. J. Dairy Sci. 74:3900-3912.

Oetzel, G. R., M. J. Fettman, D. W. Hamar, and J. D. Olson. 1991. Screening of anionic salts for palatability, effects on acid-base status, and urinary calcium excretion in dairy cows. J. Dairy Sci. 74:965-971.

Oetzel, G. R., J. Olson, C. Curtis, and M. Fettman. 1988. Ammonium chloride and ammonium sulfate for prevention of parturient paresis in dairy cows. J. Dairy Sci. 71:3302-3309.

Penner, G. B., G. Tremblay, T. Dow, and M. Oba. 2008. Timothy hay with a low dietary cation-anion difference improves calcium homeostasis in periparturient Holstein cows. J. Dairy Sci. 91:19591968.

Puntenney, S. B. 2006. The effect of prepartum anionic diets on cortisol, adiponectin, and tumour necrosis factor- $\alpha$ expression at varying levels of body mass index in preparturient dairy cows: Implications for insulin resistance. PhD Dissertation, Department of Animal Sciences, Oregon State University, Corvallis. Accessed Nov. 30, 2018. https://ir.library.oregonstate.edu/concern/ graduate_thesis_or_dissertations/th83m3366.

Rabe-Hesketh, S., and A. Skrondal. 2005. Multilevel and Longitudinal Modeling Using Stata. STATA Press, College Station, TX.

Rabiee, A. R., K. Breinhild, W. Scott, H. M. Golder, E. Block, and I. J. Lean. 2012. Effect of fat additions to diets of dairy cattle on milk production and components: A meta-analysis and metaregression. J. Dairy Sci. 95:3225-3247.

Ramos-Nieves, J. M., B. Thering, M. Waldron, P. Jardon, and T. Overton. 2009. Effects of anion supplementation to low-potassium prepartum diets on macromineral status and performance of periparturient dairy cows. J. Dairy Sci. 92:5677-5691.

Rayssiguier, Y., J. Garel, M.-J. Davicoo, and J. Barlet. 1977. Plasma parathyroid hormone and calcitonin levels in hypocalcaemic magnesium-deficient calves. Ann. Rech. Vet. 8:267-273.

Razzaghi, A., H. Aliarabi, M. Tabatabaei, A. Saki, R. Valizadeh, and P. Zamani. 2012. Effect of dietary cation-anion difference during prepartum and postpartum periods on performance, blood and urine minerals status of holstein dairy cow. Asian-Australas. J. Anim. Sci. 25:486-495.

Rérat, M., A. Philipp, H. Hess, and A. Liesegang. 2009. Effect of different potassium levels in hay on acid-base status and mineral balance in periparturient dairy cows. J. Dairy Sci. 92:6123-6133.

Rérat, M., and P. Schlegel. 2014. Effect of dietary potassium and anionic salts on acid-base and mineral status in periparturient cows. J. Anim. Physiol. Anim. Nutr. (Berl.) 98:458-466.

Rezac, D. J., E. Block, D. Weber, M. Brouk, and B. Bradford. 2014. Effects of prepartum dietary cation-anion difference and acidified coproducts on dry matter intake, serum calcium, and performance of dairy cows. J. Anim. Sci. 92:666-675.

Rodney, R. M., J. K. Hall, C. T. Westwood, P. Celi, and I. J. Lean. 2016. Precalving and early lactation factors that predict milk casein and fertility in the transition dairy cow. J. Dairy Sci. 99:75547567. 
Rodney, R. M., N. Martinez, E. Block, L. L. Hernandez, P. Celi, C. D. Nelson, J. E. P. Santos, and I. J. Lean. 2018a. Effects of prepartum dietary cation-anion difference and source of vitamin D in dairy cows: vitamin D, mineral, and bone metabolism. J. Dairy Sci. 101:2519-2543.

Rodney, R. M., N. P. Martinez, P. Celi, E. Block, P. C. Thomson, G. Wijffels, D. R. Fraser, J. E. P. Santos, and I. J. Lean. 2018b. Associations between bone and energy metabolism in cows fed diets differing in level of DCAD and supplemented with calcidiol or cholecalciferol. J. Dairy Sci. 101:6581-6601.

Sansom, B. F., R. Manston, and M. Vagg. 1983. Magnesium and milk fever. Vet. Rec. 112:447-449.

Santos, J. E. P., H. M. Golder, E. Block, and I. J. Lean. 2019. Metaanalysis of the effects of prepartum dietary cation-anion difference on performance and health of dairy cows. J. Dairy Sci. 102:21342154. https://doi.org/10.3168/jds.2018-14628.

St-Pierre, N. R. 2001. Invited review: Integrating quantitative findings from multiple studies using mixed model methodology. J. Dairy Sci. 84:741-755.

Stockdale, C. 2004. Effects of feeding magnesium sulfate to dry pregnant dairy cows with different body condition scores on intake in late gestation, periparturient blood calcium concentrations and production in early lactation. Aust. J. Exp. Agric. 44:539-546.

Tanner-Smith, E. E., and E. Tipton. 2014. Robust variance estimation with dependent effect sizes: Practical considerations including a software tutorial in Stata and SPSS. Res. Synth. Methods 5:13-30.

Thomas, J. W., and R. S. Emery. 1969. Additive nature of sodium bicarbonate and magnesium oxide on milk fat concentrations of milking cows fed restricted-roughage rations. J. Dairy Sci. $52: 1762-1769$.

Thompson, S. G., and S. J. Sharp. 1999. Explaining heterogeneity in meta-analysis: A comparison of methods. Stat. Med. 18:2693-2708.

Tucker, W. B., J. Hogue, G. Adams, M. Aslam, I. Shin, and G. Morgan. 1992. Influence of dietary cation-anion balance during the dry period on the occurrence of parturient paresis in cows fed excess calcium. J. Anim. Sci. 70:1238-1250.

Van den Noortgate, W., J. A. López-López, F. Marín-Martínez, and J. Sánchez-Meca. 2013. Three-level meta-analysis of dependent effect sizes. Behav. Res. Methods 45:576-594.

Wang, C., and D. Beede. 1992. Effects of diets magnesium on acidbase status and calcium metabolism of dry cows fed acidogenic salts. J. Dairy Sci. 75:829-836.

Weich, W., E. Block, and N. Litherland. 2013. Extended negative dietary cation-anion difference feeding does not negatively affect postpartum performance of multiparous dairy cows. J. Dairy Sci 96:5780-5792.

White, I. R., and J. Thomas. 2005. Standardized mean differences in individually-randomized and cluster-randomized trials, with applications to meta-analysis. Clin. Trials 2:141-151.

Wilkens, M. R., C. Praechter, G. Breves, and B. Schroder. 2016. Stimulating effects of a diet negative in dietary cation-anion difference on calcium absorption from the rumen in sheep. J. Anim. Physiol. Anim. Nutr. (Berl.) 100:156-166.

Wu, W. J. Liu, G. Xu, and J. Ye. 2008. Calcium homeostasis, acidbase balance, and health status in periparturient Holstein cows fed diets with low cation-anion difference. Livest. Sci. 117:7-14.

Wu, Z., J. Bernard, and S. Taylor. 2015. Effect of feeding calcareous marine algae to Holstein cows prepartum or postpartum on serum metabolites and performance. J. Dairy Sci. 98:4629-4639.

Wu, Z., J. Bernard, K. Zanzalari, and J. Chapman. 2014. Effect of feeding a negative dietary cation-anion difference diet for an extended time prepartum on postpartum serum and urine metabolites and performance. J. Dairy Sci. 97:7133-7143.

Zimpel, R., M. B. Poindexter, A. Vieira-Neto, E. Block, C. R. Staples, W. W. Thatcher, and J. E. P. Santos. 2018. Effect of dietary cation-anion difference on acid-base status and dry matter intake in dry cows. J. Dairy Sci. 101:8461-8475. 


\section{APPENDIX}

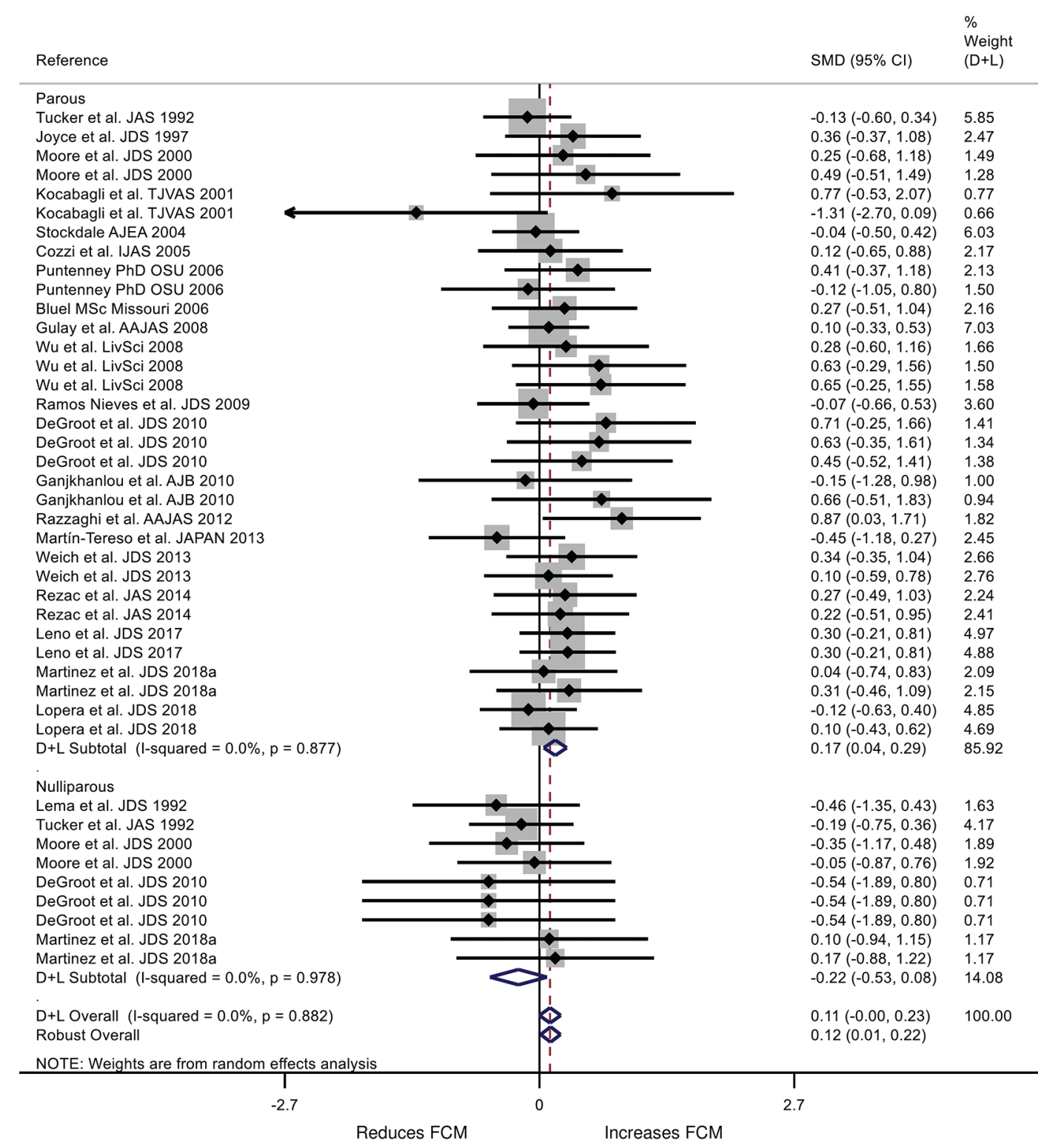

Figure A1. Forest plot of the effect size or standardized mean difference (SMD; standardized using the z-statistic) and $95 \%$ CI of the effect of a lowered DCAD intake $(\mathrm{Eq} / \mathrm{d})$ on FCM from comparisons in which the cows were stratified as parous or nulliparous. The solid vertical line represents a mean difference of zero or no effect. Points to the left of the line represent a reduction in FCM yield, whereas points to the right of the line indicate an increase in yield. Each box around the point effect represents the mean effect size for that comparison and reflects the relative weighting of the comparison to the overall effect size estimate. The larger the box, the greater the comparison contribution to the overall estimate. The weight that each comparison contributed is in the right-hand column. The upper and lower limit of the line connected to the square represents the upper and lower 95\% CI for the effect size. The overall pooled effects size or SMD and 95\% CI pooled using the DerSimonian and Laird (D+L; DerSimonian and Laird, 1986) and robust meta-analytical models (Hedges et al., 2010) methods for random effects models are indicated by the respective diamonds at the bottom. The heterogeneity measure, $I^{2}$, is a measure of variation beyond chance among treatments included in the meta-analysis. The effect of a lower DCAD intake on the change in FCM was not heterogeneous, as indicated by the $I^{2}$ of $0 \%$. 


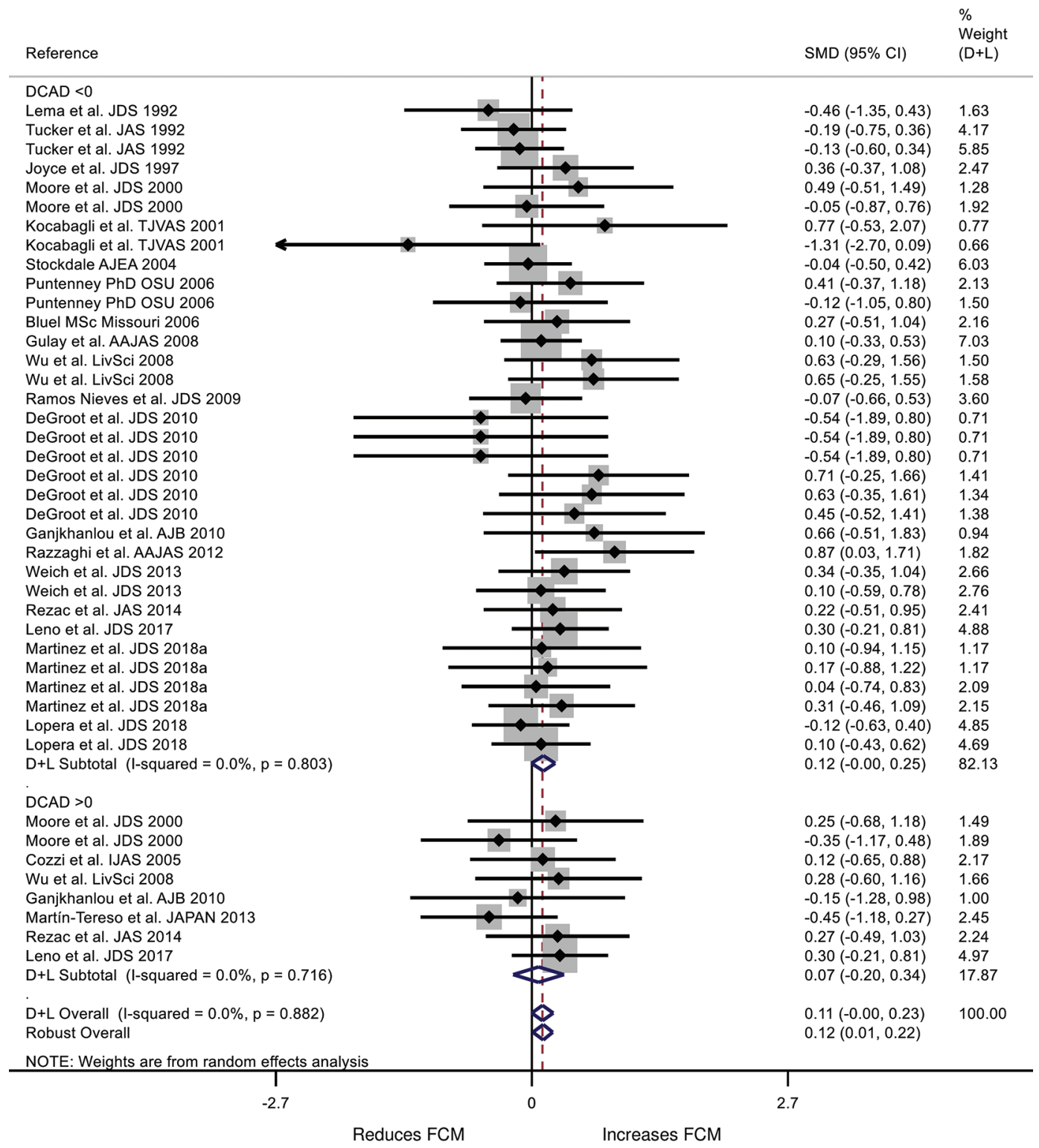

Figure A2. Forest plot of the effect size or standardized mean difference (SMD; standardized using the z-statistic) and $95 \%$ CI of the effect of a lowered DCAD intake $(\mathrm{Eq} / \mathrm{d})$ on FCM from experiments in which the treatment DCAD was either negative $(<0 \mathrm{mEq} / \mathrm{kg}$ of DM) or positive $(>0 \mathrm{mEq} / \mathrm{kg}$ of DM). The solid vertical line represents a mean difference of zero or no effect. Points to the left of the line represent a reduction in FCM yield, whereas points to the right of the line indicate an increase in yield. Each box around the point effect represents the mean effect size for that comparison and reflects the relative weighting of the comparison to the overall effect size estimate. The larger the box, the greater the comparison contribution to the overall estimate. The weight that each comparison contributed is in the right-hand column. The upper and lower limit of the line connected to the square represents the upper and lower 95\% CI for the effect size. The overall pooled effects size or SMD and 95\% CI pooled using the DerSimonian and Laird (D+L; DerSimonian and Laird, 1986) and robust meta-analytical models (Hedges et al., 2010) methods for random effects models are indicated by the respective diamonds at the bottom. The heterogeneity measure, $I^{2}$, is a measure of variation beyond chance among treatments included in the meta-analysis. The effect of a lower DCAD intake on the change in FCM was not heterogeneous, as indicated by the $I^{2}$ of $0 \%$. 


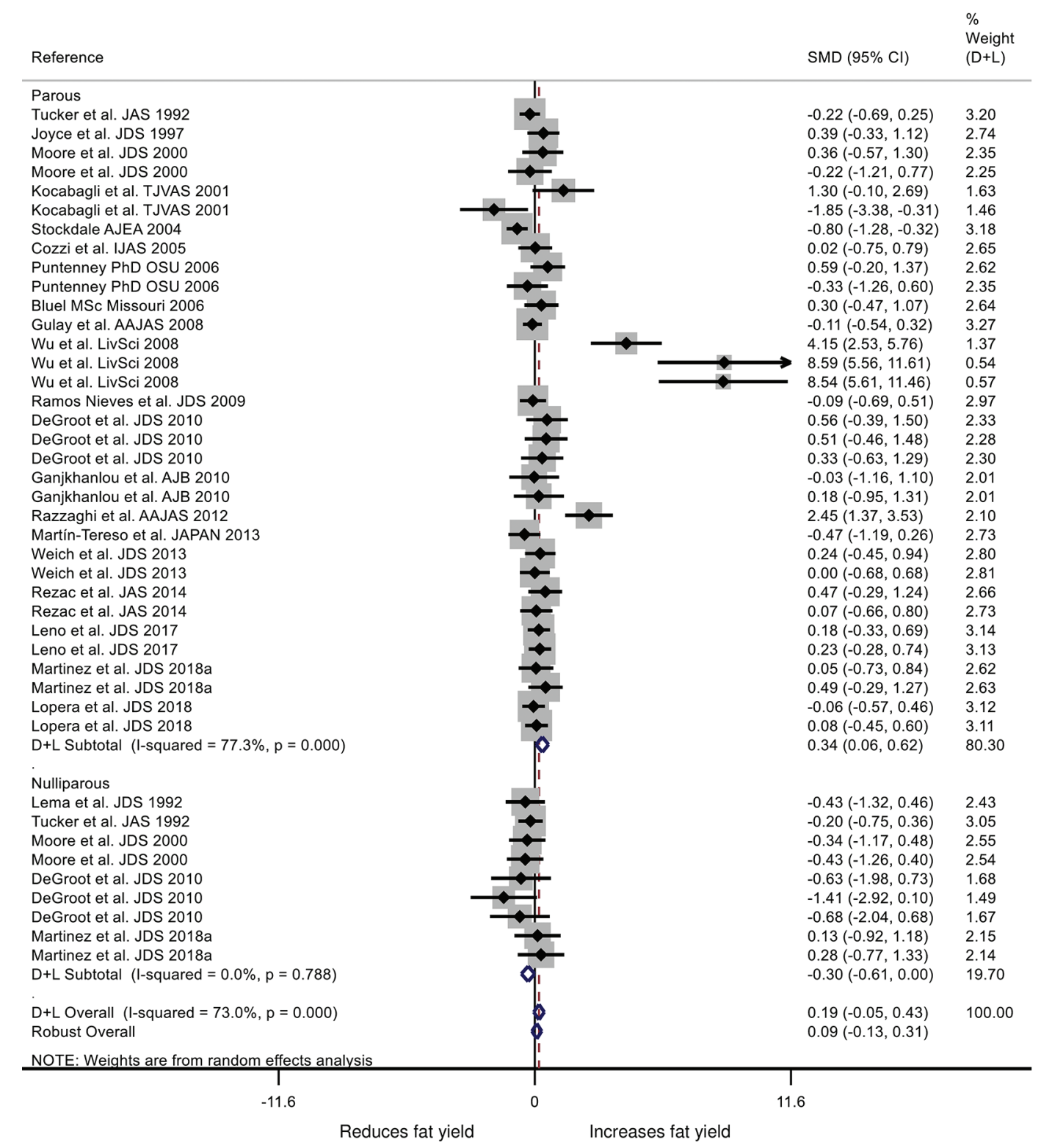

Figure A3. Forest plot of the effect size or standardized mean difference (SMD; standardized using the z-statistic) and $95 \%$ CI of the effect of a lowered DCAD intake $(\mathrm{Eq} / \mathrm{d})$ on milk fat yield from comparisons in which the cows were parous or nulliparous. The solid vertical line represents a mean difference of zero or no effect. Points to the left of the line represent a reduction in fat yield, whereas points to the right of the line indicate an increase in yield. Each box around the point effect represents the mean effect size for that comparison and reflects the relative weighting of the comparison to the overall effect size estimate. The larger the box, the greater the comparison contribution to the overall estimate. The weight that each comparison contributed is in the right-hand column. The upper and lower limit of the line connected to the square represents the upper and lower 95\% CI for the effect size. The overall pooled effects size or SMD and 95\% CI pooled using the DerSimonian and Laird (D+L; DerSimonian and Laird, 1986) and robust meta-analytical models (Hedges et al., 2010) methods for random effects models are indicated by the respective diamonds at the bottom. The heterogeneity measure, $I^{2}$, is a measure of variation beyond chance among treatments included in the meta-analysis. The effect of a lower DCAD intake on the change in fat yield was heterogeneous, as indicated by the $I^{2}$ of $73 \%$. 


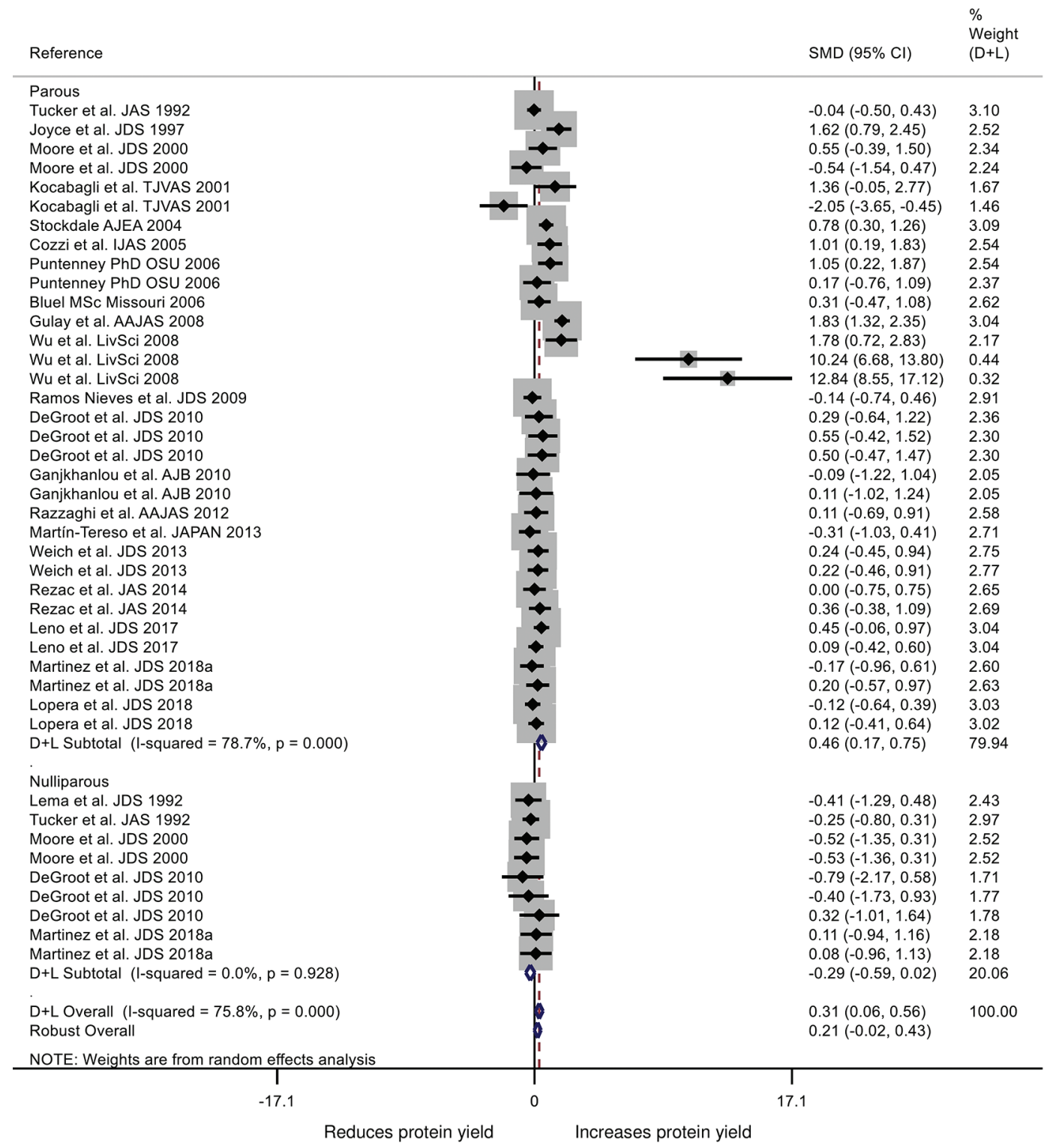

Figure A4. Forest plot of the effect size or standardized mean difference (SMD; standardized using the z-statistic) and 95\% CI of the effect of a lowered DCAD intake $(\mathrm{Eq} / \mathrm{d})$ on milk protein yield from comparisons in which the cows were parous or nulliparous. The solid vertical line represents a mean difference of zero or no effect. Points to the left of the line represent a reduction in fat yield, whereas points to the right of the line indicate an increase in yield. Each box around the point effect represents the mean effect size for that comparison and reflects the relative weighting of the comparison to the overall effect size estimate. The larger the box, the greater the comparison contribution to the overall estimate. The weight that each comparison contributed is in the right-hand column. The upper and lower limit of the line connected to the square represents the upper and lower 95\% CI for the effect size. The overall pooled effects size or SMD and 95\% CI pooled using the DerSimonian and Laird (D+L; DerSimonian and Laird, 1986) and robust meta-analytical models (Hedges et al., 2010) methods for random effects models are indicated by the respective diamonds at the bottom. The heterogeneity measure, $I^{2}$, is a measure of variation beyond chance among treatments included in the meta-analysis. The effect of a lower DCAD intake on the change in milk protein was heterogeneous, as indicated by the $I^{2}$ of $75 \%$. 


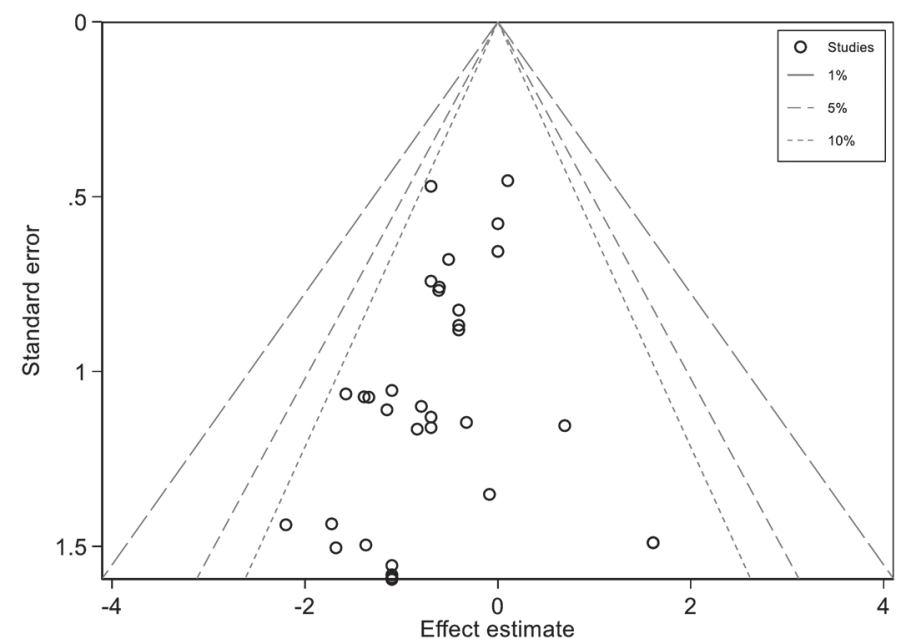

Figure A5. Contour-enhanced funnel plot for effects of a lowered DCAD intake on risk of retained placenta in dairy cows. The gray broken lines represent the 90, 95, and 99\% CI for treatment comparisons. Effect estimates from small studies will scatter more widely at the bottom of the graph and the spread narrows for larger treatments. In the absence of heterogeneity or bias, the plot should approximately resemble a symmetrical (inverted) funnel with studies lying within these lines. If bias is present, for example because smaller treatments without statistically significant effects remain unpublished, this will lead to an asymmetrical appearance of the funnel plot and a gap will be evident in a bottom corner of the graph. 